\title{
When Guests Trust Hosts for Their Words: Host Description and Trust in Sharing Economy
}

\author{
Authors: \\ Iis $\mathrm{P}$. Tussyadiah, $\mathrm{PhD}^{1}$ \\ Reader in Hospitality and Digital Experience \\ School of Hospitality and Tourism Management \\ University of Surrey \\ 56AP02 Austin Pearce Building \\ Guildford, GU2 7XH, United Kingdom \\ Phone: +44 1483684292 \\ Email: i.tussyadiah@surrey.ac.uk \\ and \\ Sangwon Park, Ph.D \\ Associate Professor \\ School of Hotel and Tourism Management \\ The Hong Kong Polytechnic University \\ 17 Science Museum Road, \\ TST East, Kowloon, Hong Kong \\ E-mail: sangwon.park@polyu.edu.hk
}

Accepted for publication in

Tourism Management

4 February 2018

${ }^{1}$ Corresponding author 


\section{Highlights}

- Two self-presentation patterns were found from Airbnb host profiles.

- Hosts present themselves as well-traveled or those with certain professions.

- Consumers demonstrated higher trust in well-traveled hosts.

- Consumers' booking intention was higher for well-traveled hosts.

- Hosts are advised to project personal strength relevant to hosting in profiles. 


\section{Graphical Abstract}

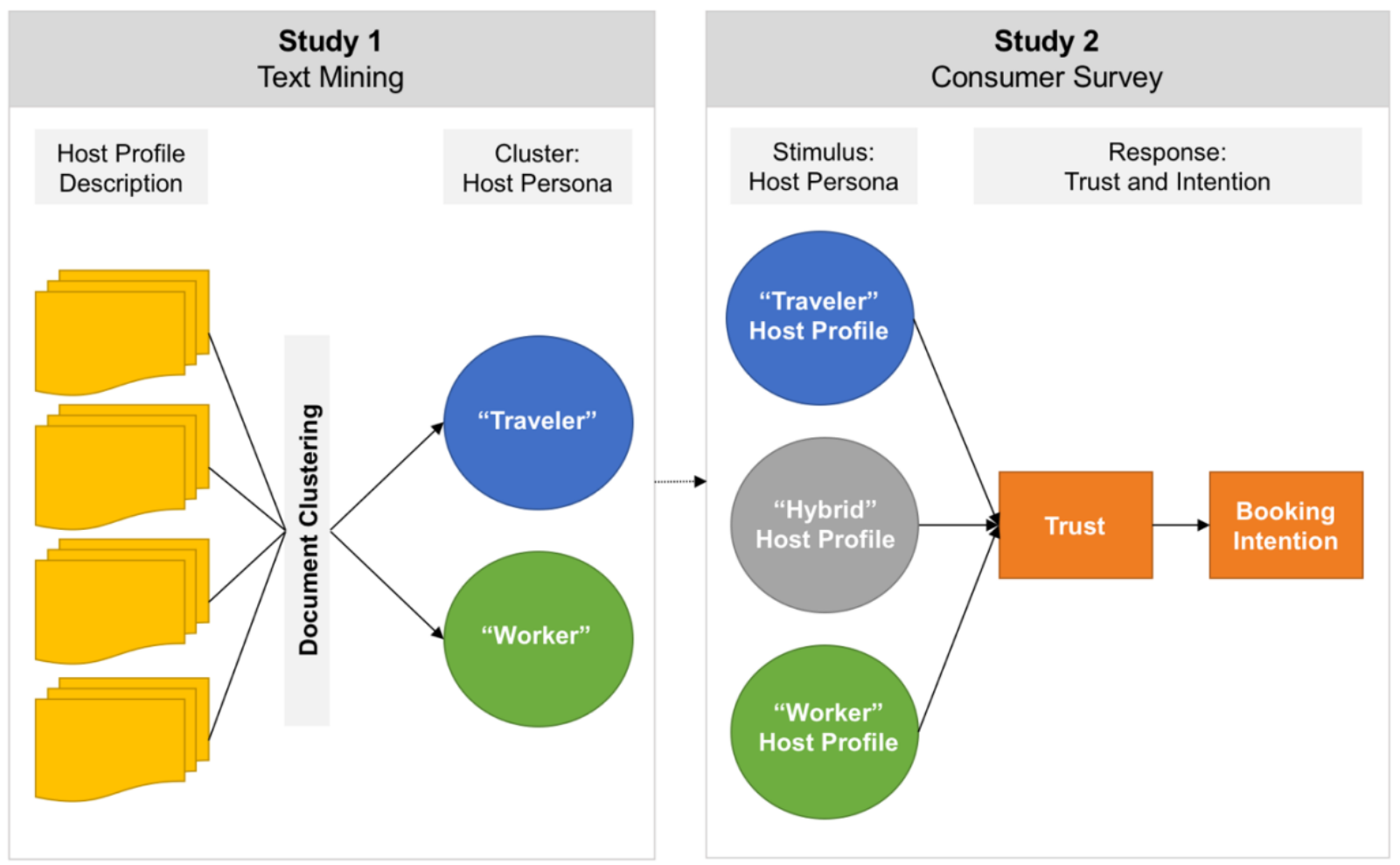




\title{
When Guests Trust Hosts for Their Words: \\ Host Description and Trust in Sharing Economy
}

\begin{abstract}
In order to better understand the dynamics of user behavior in the sharing economy platform, a multi-stage study was conducted on how Airbnb hosts articulate themselves online and how consumers respond to different host self-presentation patterns. First, using text mining techniques on a large dataset consisting descriptions of Airbnb hosts in 14 major cities in the United States, two patterns of host self-presentation were identified. Hosts generally present themselves online as (1) a well-traveled individual, eager to meet new people or (2) an individual of a certain profession. This contributes to the conceptualization of profile as promise framework for online self-presentation in mixed-mode interactions involving peer-to-peer accommodation platform. Second, consumers respond to the two host self-presentation strategies differently, demonstrating higher levels of perceived trustworthiness in and intention to book from welltraveled hosts. This has direct strategic implications for effective self-marketing of "amateur" tourism players as well as for the role of residents as resources in tourism destinations.
\end{abstract}

Keyword: Airbnb, sharing economy, peer-to-peer accommodation, host self-presentation, selfmarketing, trustworthiness 


\section{Introduction}

Peer-to-peer accommodation business continues to grow significantly (eMarketer, 2017; Fortune, 2017; PWC, 2016) and generates substantial impacts in the tourism and hospitality industry (Skift, 2017; Tussyadiah \& Pesonen, 2016), making it one of the top priorities for research in the field (Cheng, 2016a; 2016b; Guttentag, 2015; Heo, 2016; Karlsson \& Dolnicar, 2016; Tussyadiah, 2016). In order to provide a solid theoretical foundation for sharing economy as a consumption and exchange system, it is important to delineate its unique processes in comparison to that of conventional accommodation service. Therefore, a thorough investigation into the dynamics of decision-making processes in peer-to-peer accommodation is necessary. Through peer-to-peer accommodation platforms such as Airbnb, hosts and guests find each other and transact online and then, to a certain extent, interact offline during the service delivery. In order to make a decision to start the booking process, be it by contacting the host for approval or doing so through the instant booking option, potential guests are faced with a problem of evaluating not only the various attributes of the property, but also the characteristics of the hosts. Previous studies show that trust in host plays an important role in booking decision in peer-topeer accommodation platforms (Ert, Fleischer, \& Magen, 2016; Hawlitschek, Teubner, \& Weinhardt, 2016; Richardson, 2015). That is, the platform - peer-consumer - peer-provider triad in the sharing economy system generates additional layers of trust that shapes consumer choice: trust in platform and trust in host. A large body of research has examined the influence of trust in service providers on consumer choice in traditional service settings (e.g., Coulter \& Coulter, 2002; Doney \& Cannon, 1997; Johnson \& Grayson, 2005), including that of tourism and hospitality (e.g., Liu \& Zhang, 2014; Sparks \& Browning, 2011; Wang et al., 2015). In the context of platform economy, where buyers and sellers transact online using third-party 
platforms such as Amazon and eBay, the dynamics of buyer-seller trust and buyer-platform trust as well as their effects on purchase decision have also been researched widely (e.g., Chen, Zhang, \& Xu, 2009; Hong \& Cho, 2011; Pavlou \& Gefen, 2002). It is suggested that trust in host, along with trust in platform, plays a critical role in guest decision to book a particular property through peer-to-peer accommodation platforms.

Potential guests are using various cues to arrive at the expectation of hosts' trustworthiness (Deng \& Ravichandran, 2017; Ert et al., 2016). Due to the nature of the business model, some trust mechanism is built into the platform as online reputation system such that potential guests can derive information about the trustworthiness of the hosts from guest reviews (i.e., testaments to past performance, records of past deeds) and/or their responses to guest reviews (i.e., evidence of courtesy and/or service recovery strategies). Importantly, Airbnb hosts can craft an image about themselves through their online profiles. In that, they have the opportunity to shape consumer perception about their identity and character, create favorable impressions of themselves, and, thus, positively influence consumer choice. While the link between reviews and trust in the context of sharing economy has been explored in previous research (e.g., Deng \& Ravichandran, 2017; Teubner, Saade, Hawlitschek, \& Weinhardt, 2016; Yang et al., 2016), research investigating the relationships between host self-presentation and trust is relatively scant. This study aims to investigate if and how the ways hosts express themselves by crafting and posting their profile online would generate trust among prospective guests.

Specifically, this study addresses two broad research questions: (1) how hosts of peer-topeer accommodation articulate their identity online and (2) how prospective guests respond to host self-presentation practices. This study uses the theoretical foundation behind self- 
presentation strategies (e.g., Chen, 2013; Labrecque, Markos, \& Milne, 2011; Shepherd, 2005) as well as interpersonal trust (e.g., Raban, 2009) in the contexts of online interaction, social networks, and transaction or trading contexts. It follows a two-study approach by first conducting a series of text analyses on descriptions of Airbnb hosts to identify the underlying self-presentation practices and then assessing consumer perception of the trustworthiness of the hosts.

\section{Literature review}

\subsection{Online self-Presentation in mixed-mode interactions}

The strategies people use to present themselves online, through personal web pages or social media platforms, have been explored in literature as a form of self-marketing (e.g., Chen, 2013; Kim \& Tussyadiah, 2013; Labrecque et al., 2011; Shepherd, 2005). These studies suggested that consumers are applying the same marketing and branding principles originally developed for products and services to generate a favorable image of themselves online in order to achieve various goals (Chen, 2013; Schwabel, 2009). Personal branding refers to the process by which individuals differentiate themselves from others by expressing their unique value proposition and leveraging it with a consistent image across different communication platforms (Schwabel, 2009). Research on personal branding and self-marketing on the web has focused on public figures, such as in politics and entertainment (e.g., Marshall, 2010; Marwick \& Boyd, 2011; Stanyer, 2008). However, an increasing number of studies also deals with self-presentation among amateur individuals or everyday people for the purposes of seeking employment, establishing friendship, dating, or simply self-expression (Chen, 2013; Labrecque et al., 2011; Shepherd, 2005). 
Self-presentation is not only associated with the process of packaging the self, but also editing it, which entails making decisions on what information regarding self to convey and what to conceal (Toma, Hancock, \& Ellison, 2008). Drawing largely from Goffman's (1990) theory of self, literature on self-presentation in technology-mediated communication has focused on social interactions that occur exclusively online. Research on online impression management focuses on how the absence of nonverbal communication cues and the potentially asynchronous communication online eventually led to the practice of selective self-presentation (Walther, 1992; 2007; Walther \& Burgoon, 1992). In such cases, online personal identity is viewed as malleable and subject to self-censorship. This results in an optimized self-presentation opportunity for the message deliverers and idealized perception for the message receivers. Consequently, people often end up revealing themselves far more intimately than they would be inclined to do (Rheingold, 1995). However, these strategies do not work well in areas of mixedmode social relationships, when people first meet online and then move offline. Gibbs, Ellison, and Heino (2006) suggested that online self-presentation and personal branding strategies are entangled with anticipated future (face-to-face) interactions.

Peer-to-peer accommodation system provides a unique context for mixed-mode social relationships. Prospective hosts and guests communicate online using the platform to book accommodation and then interact offline during service delivery. The modality switch from online to offline communication shapes the degree of self-disclosure (e.g., Ellison, Heino, \& Gibbs, 2006; Gibbs et al., 2006). For hosts, while it is important to highlight personal strength and uniqueness to attract prospective guests, it is more important to convey an online identity that is consistent with the expected offline impression. This will result in perception of authenticity (Labrecque et al., 2011). Authenticity can be said as a match between online and 
offline identity, which transforms a sense of authenticity in online environment to reflect offline believability or an authenticity to presented self (Orsatti \& Riemer, 2012). Indeed, "feeling real" and free of psychological uncertainty between one's social roles/behaviours and one's true self is the crux of psychological component of authenticity (Reinecke \& Trepte, 2014). Social network (or sharing) sites such as online dating websites provide users with various features allowing people to share rich self-presentations (e.g., online profiles) (Ellison, 2007) and emphasise selfdisclosure through social gratifications (Trepte \& Reinecke, 2013). Self-presentation and selfdisclosure on social network websites tend to offer users chances to portray their true self as opposed to anonymous format of computer-mediated communication including chats or forums. For example, in the context of online dating environment, pressure to highlight one's positive attributes can be arisen with need to display one's true self to others in an intimate relationship (Ellison et al., 2006). Thereby, the users consider balancing the desire for positive selfpresentation with the need for accurate self-presentation based upon the likelihood of a face-toface meeting (Ellison et al., 2006). Ellison, Hancock and Toma (2011), in this vein, suggest "profile as promise" framework, asserting that online profiles are crafted to allow audience to have an expectation that "future face-to-face interaction will take place with someone that does not differ fundamentally from the person represented by the profile" (p. 12).

Kim and Lee (2011) identified two strategies from self-presentational behaviour in social media, honest and positive self-presentation. Honest self-presentation strategies place more emphasis on accuracy or authenticity. On the other hand, positive (or selective) self-presentation strategies emphasize desirability. Researchers have observed the tension between the need for accuracy and desirability, especially in situations such as online dating, where significant and long-term social relationships are the goal of personal branding (e.g., Ellison et al., 2006). 
However, in situations where social relationships are not expected to endure, such as in socialcommercial exchanges, this tension is largely unknown. Since hosts are the targets of trust in online transactions and offline service delivery, they have the burden of presenting themselves as trustworthy parties (Haas \& Deseran, 1981). Therefore, it can be proposed that hosts employ various strategies to present themselves online through their profile descriptions in order to gain trust from prospective guests.

Proposition 1. There are different identifiable patterns of online self-presentation among hosts of peer-to-peer accommodation.

\subsection{Trust within digital platforms}

In consumption situations, trust matters when the trusting expectations make a difference to a decision. Trust is defined as positive expectations regarding the conduct, motives, and intentions of trustees, which lead to a willingness to act on the basis of the trustees' words and actions (Cook \& Wall, 1980; McAllister, 1995). As suggested by Barber (1983), trust in social exchanges is based on an expectation of the persistence and fulfillment of the natural and social order, an expectation of the technically competent role performance from those involved, and an expectation that partners in social interactions will carry out their fiduciary obligations and responsibilities. That is, from a social perspective, trust is centered on moral duties. Prospective guests make a booking through a peer-to-peer accommodation platform on the confident expectations that all parties involved in the service system, including the hosts and the company behind the online platform (e.g., Airbnb), will act competently and dutifully. From a rational perspective, trust centers on self-interest; an increase in trust will decrease the transaction cost associated with protecting self from the possibilities of others' opportunistic behavior (Lauer \& 
Deng, 2007). Trust is, thus, defined as the willingness of trustors to be vulnerable to the actions of trustees based on the expectations that trustees will perform important actions irrespective of the ability to monitor them (Mayer, Davis, \& Schoorman, 1995).

In general, trust is partially a product of people's capacity to assess the trustworthiness of others (Sheppard \& Sherman, 1998). In deciding whether or not to trust hosts in peer-to-peer accommodation platforms, prospective guests make an estimation of hosts' characteristics that reflect trustworthiness. Sztompka (1999) suggested two types of information on which people make such trusting decisions: the inherent traits of the trustees, which lead to primary trustworthiness, and the context in which the trustees operate, which leads to derived trustworthiness. In estimating primary trustworthiness, people employ three criteria: reputation, performance, and appearance (Sztompka, 1999). Reputation is associated with record of past deeds, consistency of the record, and a certain unity of conduct over time. Performance refers to actual deeds, present conduct, and currently obtained results. Appearance is associated with one's look and self-presentation, which in offline contexts includes how people dress, bodily discipline and civility, as well as ascribed statuses. Based on this conceptualization, the information people can use to estimate the primary trustworthiness of peer-to-peer accommodation hosts include reviews on past and most recent services (to estimate reputation and performance) as well as host profiles (to estimate appearance). Further, trust is viewed as an expectation that others will handle their volition in keeping with the personalities they have presented and made socially visible (Luhmann, 1979). This infers that trusting hosts means expecting hosts to act in accordance with the persona they portray through their profile description as well as their reputation. Therefore, it can be suggested that the ways hosts 
articulate themselves online can have an influence on prospective guests' estimation of the trustworthiness of the hosts.

Mayer et al. (1995) proposed the framework of the facets of trustworthiness, which consist of three attributes and characteristics of trustees that predict trust: (1) trustees have the required skills and characteristics that enable them to be perceived as competent within a specific domain (competence or ability), (2) trustees are believed to feel interpersonal care and concern and be willing to do good to trustors beyond egocentric profit motive (benevolence), and (3) trustees are perceived to adhere to a set of principles that trustors consider to make the trustees dependable and reliable (integrity). Various studies have applied the three concepts as a means to assess trustworthiness of exchange partners, including individuals and organizations (e.g., firms), in offline and online settings (e.g., Cheung \& Lee, 2001; Gefen, 2002; Lee \& Turban, 2001; Ratnasingam \& Pavlou, 2003) Indeed, while initially proposed for face-to-face interpersonal contexts, these dimensions of trustworthiness (also referred to as trusting beliefs) can be adapted to measure online trust, where the object of trust is a person or a technology-deploying organization. For example, McKnight, Choudhury and Kacmar (2002a; 2002b) assessed consumers' trusting beliefs toward a web vendor, which consist of perception of competence, benevolence and integrity, based on the company profile portrayed on a hypothetical website. Similarly, Lauer and Deng (2007) estimated the three dimensions of trustworthiness of a company in the context of e-commerce based on the evaluation of the company's privacy policy on its website. Finally, Raban (2009) identified the role of self-presentation, specifically cues in textual communication, in online trust between users in a "Question-and-Answer" (Q\&A) online community, which leads to social and monetary feedback. Therefore, it can be suggested that 
prospective guests will expect certain levels of competence, benevolence, and integrity from the information they can find about the hosts on peer-to-peer accommodation platforms online. Proposition 2. Hosts' online self-presentation patterns will result in different levels of perceived trustworthiness among prospective guests.

Previous studies suggested the antecedents and consequences of trusting beliefs on online and offline consumer trust (Beldad, de Jong, \& Steelhouder, 2010; Hoffman, Novak, \& Peralta, 1999). In online platform contexts, trust in online sellers is influenced by trust in platform providers or intermediaries (Chen et al., 2009). Studies also found that trusting beliefs lead to trusting intentions. McKnight et al., (2002a; 2002b) found the positive impact of trusting beliefs on willingness to depend on and transact with an online vendor. Lauer and Deng (2007) identified that perceived trustworthiness of an online company positively influenced trust in the company, which results in customer truthfulness and loyalty. Additionally, studies found the individual dimensions of trustworthiness to have an effect on different trusting intentions. For example, Gefen (2002) discovered that perceived ability of online vendors leads to window shopping intention, while perceived integrity to purchase intention. While the aim of this study is not to test the relationships between perceived trustworthiness (or its individual dimensions) and its antecedents and/or consequences, it is worth noting the findings from previous research to support the significance of studying perceived trustworthiness of peer-to-peer accommodation hosts. Given the importance of trusting beliefs in generating trusting intentions, a better understanding on how hosts can induce positive expectations among prospective hosts is critical to assess the dynamics of trust system and consumer decision making processes in peer-to-peer accommodation platforms. 


\section{Methodology}

\subsection{Study 1: Host self-presentation patterns}

The aim of Study 1 is to identify patterns of hosts' self-presentation on the leading peer-to-peer accommodation platform, Airbnb. Dataset containing textual information of Airbnb hosts 14 cities in the United States were obtained from InsideAirbnb.com (2015). InsideAirbnb.com sourced the dataset from publicly available information on Airbnb website, served by Amazon S3 "bucket." In order to analyze the underlying self-presentation strategies among hosts who are not professional accommodation businesses, this study excluded hosts who have more than one listing on Airbnb. A total of 31,119 Airbnb host descriptions were selected. A text analytics software, KH Coder (Higuchi, 2017a; 2017b), was used to analyze the large textual dataset. First, the text corpus was pre-processed for further analysis, using Stanford POS tagger (Toutanova et al., 2003). This pre-processing comprises of four sequential steps: tokenization (i.e., decomposing a stream of text into words, phrases, symbols, and other meaningful parts called tokens), elimination of stop words (i.e., detaching frequently occurring non-context-bearing, common words, such as definite or indefinite articles and auxiliary verbs, including "a", "an", "the", etc.), part-of-speech (POS) tagging (i.e., allocating parts of speech to each word, such as noun, verb, adjective, and so on, based on both its definition and its context), and lemmatization (i.e., conflating tokens to their root form, such as "booking" and "booked" into "book"). The study conducted by Tussyadiah and Zach (2017) comprehensively explained the relevant terminologies used in this study. The results of pre-processing are presented in Table 1, which details the total number of tokens, word types, mean term frequency (TF) and a standard deviation of TF for 14 cities in the US. As seen in Table 1 New York, NY has the most number 
of Airbnb hosts across fourteen cities (12,175 documents), followed by Los Angeles, CA (5,278), San Francisco, CA (2,581), Chicago, IL (1,712), and Austin, TX (1,681).

Then, a series of hierarchical cluster analyses (i.e., document clustering) were conducted for each city. Based on the dissimilarity matrices and agglomeration schedules as well as number of documents classified into the different clusters across the different cities, the 2-cluster solution appears to have higher accuracy in terms of self-presentation patterns than the 4-cluster solution (see Table 2). Therefore, results from 2-cluster solution were considered for further studies. Only a small fraction of reviews in the documents (less than $1 \%$ of the data) does not belong to any of the clusters.

[Please insert Table 1 and 2 about here]

The next step was to classify a set of documents having similar appearance patterns in order to identify the differences in how Airbnb hosts communicate their self-identity online. A hierarchical cluster analysis was applied with Ward's criterion and Jaccard Coefficient as distance measure (Finch, 2005). Furthermore, in order to obtain better insights regarding the clusters of host descriptions, word co-occurrence networks were developed using Jaccard Coefficient of word pairs to determine the edges of the network and Fruchterman and Reingold's (1991) algorithm to determine the layout of the network. Co-occurrence networks developed from the top frequency words belonging to the two clusters in the dataset from Austin, TX, Chicago, IL, and New York, NY are presented in Figures 1 - 3. Size of nodes indicates term frequency. Thickness of edges indicates strength of connections (i.e., extent of similarity) between word pairs. Color of nodes indicates communities in the network, which were detected using random walk method (Pons \& Latapy, 2005). Word communities, the densely connected sub-graphs in the network, can be interpreted as representation of themes from the text corpus. It 
is important to note that the researchers also conducted analyses on the top frequency words and co-occurrence networks of all cities in the dataset, but the rest are not included in manuscript due to space limitation.

[Please insert Figure 1, 2, and 3 about here]

It can be observed from the top words (see Tables A1 - A3 in Appendix A) that similar distribution of top words makes up the two clusters in three cities. For Cluster 1 in Austin and New York and Cluster 2 in Chicago, among the important top words are "love," "live," "travel," "people," and "new." The other cluster consists of words such as "professional," "artist," "designer," "photographer," and "student." Based on the list of words alone, it can be suggested that host descriptions in one cluster are dominated by themes related to their love for travel and meeting new people, while those in the other cluster by themes associated with host professions. This is supported by the patterns represented in the word co-occurrence networks (Figures 1-3). Therefore, it can be concluded that peer-to-peer accommodation hosts present themselves online following two broad patterns, which can be presented into two host personae: Persona 1, referred to as 'Travelers' herein for simplification, consisting of hosts who personify themselves as welltraveled individuals who are eager to meet new people, and Persona 2, called 'Workers' herein, consisting of hosts who identify themselves as working professionals.

Looking further into the list and associations of the top words, host descriptions belonging to Persona 1: "Travelers" also contain presentation regarding competence in hosting guests, with clearly-defined subgraphs corresponding to knowledge about and experience living in the city, as well as recommendation regarding things to do in the neighborhood (e.g., favorite places). However, the degree of self-disclosure is rather low, indicated by the absence of personal characteristics such as age, profession, or marital status in the top words. Therefore, it 
can be suggested that the underlying strategy behind Persona 1: "Travelers" is to project an identity that fits for the role, a host, by highlighting their resourcefulness and empathy for the traveling guests, offering travel experience, recommendation, and social connection. On the other hand, the word co-occurrence networks of Persona 2: "Workers" show disjointed subgraphs around different types of host professions and industry (e.g., "illustrator," "graphic," “designer," “photographer") or a hobby (e.g., "singer," "actor," "reading," "gardening”), but less on hosting-related information. Some top words reveal the personal characteristics of the host, such as gender ("male," "man"), age ("mid," "twenty"), marital status ("wife"), etc., implying a higher degree of self-disclosure. Since work has long been considered a principal source of identity to many (Fryers, 2006), and that a majority of American workers get a sense of selfidentity from their job (Gallup, 2014), it can be suggested that self-presentation strategy associated with Persona 2: "Workers" is to project personal identity, presenting self as a peer in the peer-to-peer system. It is important to note that additional clusters in the 4-cluster solutions are derivatives of the two personae (e.g., "Workers" with niche professions such as doctors, bankers, and lawyers), but do not demonstrate different patterns of self-presentation strategies.

\subsection{Study 2: Host personae, perceived trustworthiness, and intention to book}

The objective of Study 2 is to understand consumers' responses to the different ways Airbnb hosts present themselves online (i.e., host personae). Specifically, this study examines if the different personae would result in different levels of perceived trustworthiness of the hosts, including perceived ability, benevolence, and integrity, and, subsequently, likelihood to book accommodation from the hosts. 


\subsubsection{Pilot test: Confirmation of host personae}

Before the main study was conducted, a pilot test was run in order to examine if respondents can (1) correctly identify host personae based upon the host descriptions and (2) confirm the suitability of the descriptions as a proper stimulus for the following main studies. Actual host descriptions, one from each cluster, were randomly selected from the dataset and presented in a randomized order as stimuli in within-subject experimental design (see stimuli in Appendix B). After reading the descriptions, respondents were asked to classify the host into either Persona 1 ("Host is well-traveled and eager to meet new people.") or Persona 2 ("Host is a working professional."). We carefully designed the study to minimize confounding effects that can be derived from survey and/or response errors. First, in order to manage bias related with the context of a specific destination, three types of questionnaires were developed for three separate cities: New York in NY, Chicago in IL, and Austin in TX. Second, with the aim of reducing possible sentiment bias resulting from host names, following Dodds et al.’s (2011) hedonometrics study, all host names were changed into names that score 5 (i.e., neutral in sentiments) on a valence scale of $1-9$ : Neil for male and Marjorie for female. The questionnaire was distributed via Amazon Mechanical Turk (AMT), targeting users residing in the United States. As previous studies have shown that users with high reputation (95\% or higher in approval rating) produce high quality data (Peer, Vosgerau, \& Acquisti, 2014), the link to the questionnaire was only made available to MTurk users with approval rating above $98 \%$. In order to target travelers, only those who have traveled in the past six months and are familiar with peer-to-peer accommodation services were allowed to continue to answer the survey. Respondents were randomly assigned to answer one of the three questionnaires. This effort 
resulted in 101 responses for New York and 100 responses for two other cities, respectively $(N=$ 301). All respondents received US\$.75 (seventy-five cents) upon completion of the survey.

Some respondents had visited the city portrayed in the stimuli: 71 had visited New York, 41 had visited Chicago, and 24 had visited Austin. The majority of respondents (81\%) had stayed in Airbnb or other similar peer-to-peer accommodation services before; $57 \%$ of them had their most recent stay within the last six months. Of those who had not stayed in a peer-to-peer accommodation, they were moderately familiar with the service $($ Mean $=2.76$, St. Dev. $=1.011)$. As presented in Table 3, the majority of respondents classified host descriptions correctly into the two personae. On average, the accuracy is $92 \%$ of for New York and Chicago and $94 \%$ for Austin. In order to assess the reliability of agreement between respondents in classifying the stimuli (i.e., inter-rater reliability), Fleiss’ Kappa value (Fleiss, 1971) was calculated for each destination. All three studies demonstrated substantial agreement $(\kappa>.61)(.69$ for New York, .70 for Chicago, and .75 for Austin, $p<0.001$ ), indicating tolerable reliability and ultimately confirm the experimental stimuli to be used for further studies (Landis \& Koch, 1977).

[Please insert Table 3 about here]

\subsubsection{The main study}

In order to address the research questions, stimuli that produced the highest agreement rating for each persona in the pilot test (i.e., Persona 1: "Traveler" from Chicago and Persona 2: "Worker" from New York) were used in a follow-up main study with between-subject design (See Appendix $\mathrm{C}$ for questionnaire). Host names, Neil for male and Marjorie for female, both having neutral sentiment (Dodds et al., 2011), were used to represent gender of the hosts. Respondents were presented one of two host descriptions and asked to rate the host in terms of trustworthiness. In order to assess the perceived trustworthiness of hosts as a response to host 
personae, scales measuring trusting beliefs: ability, benevolence, and integrity, were derived from previous studies (Colquitt \& Rodell, 2011; Ridings, Gefen, \& Arinze, 2002; Walsh \& Beatty, 2007) and adapted to peer-to-peer accommodation context (see Table 4). Then, they were asked to rate the likelihood to book from the host given a good match between the property and their preference. All responses were presented in a 5-point scale ranging from 1 (strongly disagree or extremely unlikely) to 5 (strongly agree or extremely likely). Respondents were also asked to provide their travel behaviors, experiences and familiarity with peer-to-peer accommodation, and demographic characteristics. The questionnaire was distributed online via AMT targeting consumers who reside in the United States with AMT approval rating above $98 \%$, resulted in 800 responses. All respondents received US\$.40 (forty cents) upon completion of the survey.

[Please insert Table 4 about here]

About 59\% of respondents are male and over $70 \%$ of them are between the ages of 25 and 44 years old. About half (44.6\%) of the subjects obtained a 4-year college degree. With regard to annual household income, $68 \%$ of them receive $\$ 70,000$ or below. In terms of accommodation experiences, the majority of respondents (74.8\%) had stayed in Airbnb or other similar peer-to-peer accommodation services before; $58.1 \%$ of them had the most recent stay within the last six months. Of those who had not stayed in a peer-to-peer accommodation, they were moderately familiar with the service $($ Mean $=2.82$, St. Dev. $=1.04)$.

Partial Least Square (PLS) was employed to assess the measurement model by considering discriminant and convergent validities as well as reliability. It is important to note that this study does not aim to test theory development, which is the main purpose of using the covariance-based structural equation modelling (e.g., AMOS). Indeed, the key purpose of this 
research is to identify factors enhancing the variance explained in the outcome variable, which, in this research, is trusting intention. This is consistent to the rationale of PLS employing a principal component analysis to maximize the extent of variance accounting for the endogenous variables, rather than developing a covariance matrix (or reproducing the theoretical model) in covariance-based SEM (Chin, Marcolin, \& Newsted, 2003).

In addition, all measurements were applied from extant studies that suggested acceptable levels of reliability and validity. Thus, it is appropriate to carry out a confirmatory approach to an analysis, instead of an exploratory method. To do so, this study focused on cross-loadings of Confirmatory Factor Analysis (CFA), Average Variance Extracted (AVE) with cut-off value over 0.50, and latent correlation analysis (Chin, 2010). Additionally, both Cronbach's alpha and Composite Reliability (CR) on the basis of consistency reliability were estimated with a cut-off level of 0.80 (Hair, Ringle, \& Sarstedt, 2011). Given the measurements were confirmed to be in acceptable estimations, the group comparisons between Persona 1: "Travelers" and Persona 2: "Workers" were conducted using t-tests. Meanwhile, as part of robustness test, we checked potential existence of confounding effects that may cause group differences in terms of past accommodation experiences and demographic characteristics (Sönmez \& Graefe, 1998).

Table 5 presents the results of CFA to estimate the measurements for determining each construct. It is found that all of indicator reliability (or loadings) are over the cut-off of 0.70 . This implies that the factor loadings on the corresponding constructs are much higher than the ones on other principal constructs, which confirms the discriminant validity. The square root of AVEs was then calculated to assess the convergent validity for the individual constructs (see Table 6).

[Please insert Table 5 about here] 
The results of the analysis show that the AVEs of each construct are larger than the squared cross-correlations of other constructs, which confirms discriminant validity. The values of AVEs are over 0.70. This implies that the variables explain the indicators more than the error variances, which confirms the convergent validity. Two types of reliability tests, Cronbach's Alpha and composite reliability, were estimated. All values are over 0.75 , which indicate sufficiently high levels to satisfy tolerable reliability (Hair et al., 2011). Accordingly, it can be confirmed that the measurements for each construct are validated and reliable in acceptable levels.

[Please insert Table 6 about here]

There were significant differences of perceived trustworthiness and the likelihood to book an accommodation between the different host personae. As shown at Table 7, consumers are likely to perceive higher levels of trust to hosts who described themselves as Persona 1:

"Travelers" than those as Persona 2: "Workers." Specifically, people who responded to Persona 1: "Travelers" show higher values in terms of trust in platform $($ Mean $=3.90)$, integrity $($ Mean $=$ 4.02), benevolence $($ Mean $=4.23)$, and ability $($ Mean $=4.39)$ compared to those engaged with Persona 2: "Workers" (Mean $=3.79,3.94,3.51$, and 3.97, respectively). Consistently, hosts who described themselves as well-traveled and eager to meet new people induce a higher likelihood to book $($ Mean $=4.26)$ than those who presented themselves as a working professional $($ Mean $=$ 3.99, $p<0.001)$.

[Please insert Table 7 about here]

It is important to verify that the results of the group differences do not include the effects from other aspects that were not manipulated in the study, also called confounding variables (Ewert \& Sibthorp, 2009). Based upon reviewing relevant literature that discussed the potential 
factors influencing perceived trust, we compared previous peer-to-peer accommodation experiences and demographic characteristics between respondents who are assigned into the two personae, respectively. As presented in Table 8, no significant difference was found in the results. This implies that confounding effects on the significant findings of group differences are restricted.

[Please insert Table 8 about here]

\subsubsection{Additional study: A new persona}

We carried out an additional study in order to understand consumer responses to a host persona with combined characteristics of Persona 1: "Travelers" and Persona 2: "Workers", called herein as Persona 3: "Hybrid". To do so, a host description reflecting a hybrid persona was developed by combining description of their professional affiliation (adapted from "Workers") and explorative personality (adapted from "Travelers"), especially with regards to hosting competence (see Appendix B). We then compared consumer perception of "Hybrid" with that of "Travelers" and "Workers" personae, respectively. A series of identical procedures used in Study 2 was applied to collect the data, which results in a total of 279 responses. About $60 \%$ of the subjects are male, and around half are aged between 25 and 34 years old. Approximately, $43 \%$ of respondents obtained a 4-year college degree.

Consumer trust (i.e., integrity, benevolence, and ability) and booking intention were compared across Airbnb hosts' personae: "Travelers," "Workers," and "Hybrid." Of them, significant differences appeared in terms of benevolence $(\mathrm{F}-\mathrm{value}=125.84, p<0.001)$, ability $(\mathrm{F}$-value $=52.25, p<0.001)$ and trusting intention $(\mathrm{F}$-value $=11.61, p<0.001)($ see Figure 4$)$. Consumers who read the description of Persona 1: "Travelers" tend to show the highest perception of benevolence, ability, and booking intention, followed by those who have engaged 
with Persona 3: "Hybrid" and Persona 2: "Workers" hosts. More specifically, applying a Duncan method for the post-hoc analysis, the mean values of ability and trusting intention between Persona 3: "Hybrid" and Persona 2: "Workers" are not statistically different. However, the mean values of all three variables of Persona 1: "Travelers" are statistically different to those of both Persona 3: "Hybrid" and Persona 2: "Workers."

[Please insert Figure 4 about here]

\section{Conclusion and implications}

The rising significance of sharing economy in the tourism and hospitality industry calls for an extensive investigation into the unique processes of peer exchanges and service experiences involving mixed-mode interactions, online and offline. Specifically, peer-to-peer accommodation services involve not only transactions between non-business entities (i.e., individuals) online, facilitated by third-party platform providers such as Airbnb, the use of peer-to-peer accommodation often involves sleeping in a bedroom of a stranger. Hence, trust between prospective guests and hosts has a significant role in this new service system. For peer-to-peer accommodation hosts, being considered trustworthy by potential guests is key to thrive in this business. However, unlike conventional hotel companies who regularly market themselves strategically to appeal to potential customers, it is largely unknown if individual hosts employ self-marketing strategies to achieve this outcome. This paper provides a closer look at patterns of self-presentation among Airbnb hosts in major cities in the United States to identify the ways hosts articulate their identity online. Further, multiple studies were conducted to test how these different self-presentation strategies result in consumer trust and likelihood of being selected at the point of booking decision. The findings support further conceptualization of self-presentation 
strategies adopted by "amateur individuals" in their capacity as (paid) service provider and in mixed-mode interactions context. Further, the results also provide empirical evidence effectiveness of different self-presentation strategies in inducing perceived trustworthiness and booking intention.

Using text mining techniques to analyze Airbnb host descriptions in major US cities, this study identified two broad patterns in host self-presentation based on the words they are using to describe themselves online. In the first cluster, a group of hosts paints a picture of a well-traveled individual who is eager to meet new people and show all that the destination has to offer. This pattern indicates an underlying strategy for peer-to-peer accommodation hosts to portray themselves as a host with knowledge about the "ins and outs" of the destination and expansive experience of traveling, allowing them to understand and feel empathetic toward fellow travelers (i.e., guests). These host descriptions carry a "promise" of experienced travelers turning into attentive hosts, implying an emphasis on desirability, while being relatively low on selfdisclosure. In the second cluster, host descriptions contain more personal information, particularly highlighting their profession, representing a higher degree of self-disclosure. It is suggested that because profession can be a main source of personal identity, these hosts are projecting self as regular individuals. As previous studies suggest the need to balance between desirability and authenticity in self-presentation involving mixed-mode interactions (Ellison et al., 2006; Gibbs et al., 2006; Labrecque et al., 2011), the identification of these two patterns implies opportunities to assess if one is more effective in bringing about consumer trust than the other.

In the second study, consumer responses to the two patterns of host self-presentation were compared in terms of trusting beliefs, which include aspects of ability, benevolence, and 
integrity, as well as trusting intention. It was identified that consumers who are exposed to host description belonging to Persona 1: "Travelers" perceived a higher level of trust in terms of integrity, benevolence and ability compared to those exposed to Persona 2: "Worker". Importantly, consumers also rated higher for likelihood to book from the host in Persona 1: "Travelers" compared to that of Persona 2: "Workers". This implies that a host who is portrayed as well-traveled and eager to meet new people is considered more trustworthy and desirable compared those who disclose their profession as personal identity. Further, in order to ensure that the source of the significant difference in perceived trustworthiness is the host's travel experience and eagerness to meet new people instead of information related to hosting competence (e.g., knowledge about city), a hybrid persona was created by combining description of profession as personal identity and information related to hosting competence. The results suggest that while Persona 1: "Travelers" still shows the highest scores in terms of benevolence, ability, and trusting intention, the hybrid persona seems to perform better than the Persona 2: "Workers." This implies the important role of hosts' travel experience in the evaluation of trustworthiness among "fellow" travelers. It can be suggested that the fact that hosts have experienced similar situations as the prospective guests (i.e., visiting new destinations, finding accommodation, etc.) gives a new meaning to renting from (and staying with) peer travelers. As this study includes profiles from hosts who have one listing at the time of data collection, the results represent self-presentation behavior of peer-to-peer accommodation hosts who are "amateur" individuals as opposed to professional accommodation providers. The managerial implications of these findings are twofold. First, while about half the hosts follow a somewhat typical approach to writing user profiles in online communities, including information about their profession, age, marital/family status, hobby, etc., the rest project their image to 
reflect their role as a (desirable) host through their profile. In describing themselves, these hosts project personal strength that is highly relevant to hosting (i.e., well-traveled, open to meet new people, knowledgeable about neighborhoods). This identifiable pattern indicates that although they are not conventional business entities, but nonprofessional players in the industry, they behave strategically to market themselves in the sharing economy platform. For tourism destinations, the important implication is that residents who are renting out their property to tourists act as destination "ambassadors" and should be considered as additional resources in tourism management. Second, the significant difference in perceived trustworthiness between consumers who are exposed to Persona 1: "Travelers" and those to Persona 2: "Worker" has a direct implication with regards to the effective self-marketing approach, which is useful for peerto-peer accommodation hosts. According to the "profile as promise" framework (Ellison et al., 2011), profiles serve as a psychological contract between hosts and prospective guests, in that hosts promise aspects of the self that they believe are feasible during future service delivery. As evident in the results from Study 2, consumers trust a "well-traveled" host more than a “designer/doctor/lawyer" host, implying that communicating hosting-related information carries more "promise" than personal information. Furthermore, in light of a higher perception of competence in Persona 3: "Hybrid" compared to Persona 2: "Workers," it can be suggested for peer-to-peer accommodation hosts that adding statements that project their resourcefulness (e.g., knowledge about the city and neighborhood) can be effective in inducing perceived ability, which shapes the overall trustworthiness.

Theoretically, this study contributes to discussions on sharing economy in tourism literature by revealing the strategic self-marketing behavior of peer-to-peer accommodation hosts. Specifically, the findings contribute to our understanding of self-presentation strategies in 
mixed-mode interactions in the context of peer-to-peer service platform, where prospective tourists refer to online profile of residents (hosts) to make accommodation decision with the expectation of staying (and interacting with them) in their property. That is, apart from typical hotel marketing strategies targeted to form people's expectations of service quality associated with brand reputation, an understanding of the strategic mechanism in the sharing economy to generate trust from prospective guests is crucial. Indeed, this study reinforces the framework of "profile as promise" suggested in studies on self-presentation in interactions involving online and offline modalities (e.g., Ellison et al., 2006; 2011; Gibbs et al., 2006). Importantly, this study clarifies the strategic behavior of hosts in sharing economy, particularly with regards to selfmarketing, filling the research gap suggested by previous research on sharing economy in the context of tourism and hospitality (e.g., Cheng, 2016a; Li, Moreno, \& Zhang, 2015). Further, the results demonstrating the different levels of perceived trustworthiness and booking intention induced by the two host self-presentation patterns contributes to a better understanding on hostrelated factors that influence tourists' decisions to book accommodation. This enriches the discussion on decision-making process in the emerging peer-to-peer economy in tourism literature.

Despite the contribution, this study has several limitations that should be addressed by future research. Firstly, in stimulating perceived trustworthiness and booking intention, this research did not consider other cues in host profiles, such as pictures, reviews, and other demographic characteristics, as previous studies have studied these aspects separately (e.g., Deng \& Ravichandran, 2017; Ert et al., 2016). Future studies should combine different aspects of host profiles to identify the importance of host description relative to pictures or other identifiers in inducing trust. Secondly, this study did not consider the variation in the length of host 
descriptions, even though the presented stimuli fit the average length of documents in the corpus. In order to test the effects of profile length (and level of details) in host profiles, future studies should test consumer responses to variable lengths in host descriptions. Finally, the stimuli used to solicit consumers' booking intention were made independent from the property characteristics, assuming that the property matches consumer's criteria. Since property characteristics on peerto-peer accommodation platform are highly variable, future studies should consider the weight of trust in host relative to property characteristics in influencing booking decision. 


\section{References}

Barber, B. (1983). The Logic and Limits of Trust. New Brunswick: Rutgers University Press.

Beldad, A., de Jong, M., \& Steehouder, M. (2010). How shall I trust the faceless and the intangible? A literature review on the antecedents of online trust. Computers in Human Behavior, 26(5), 857-869.

Ellison, N. B. (2007). Social networking sites: Definition, history, and scholarship. Journal of Computer-Mediated Communication, 13, 210-230.

Chen, C.-P. (2013). Exploring personal branding on YouTube. Journal of Internet Commerce, 12(4), 332-347.

Chen, J., Zhang, C., \& Xu, Y. (2009). The role of mutual trust in building members' loyalty to a C2C platform provider. International Journal of Electronic Commerce, 14(1), 147-171.

Cheng, M. (2016a). Current sharing economy media discourse in tourism. Annals of Tourism Research, 60, 111-114.

Cheng, M. (2016b). Sharing economy: A review and agenda for future research. International Journal of Hospitality Management, 57, 60-70.

Cheung, C. M. C., \& Lee, M. K. O. (2001). Understanding consumer trust in Internet shopping: A multidisciplinary approach. Journal of the American Society for Information Science and Technology, 57(4), 479-492.

Chin, W. W. (2010). How to write up and report PLS analyses. In Handbook of partial least squares (pp. 655-690). Springer Berlin Heidelberg.

Chin, W. W., Marcolin, B. L., \& Newsted, P. R. (2003). A partial least squares latent variable modeling approach for measuring interaction effects: Results from a Monte Carlo 
simulation study and an electronic-mail emotion/adoption study. Information Systems Research, 14(2), 189-217.

Coulter, K. S., \& Coulter, R. A. (2002). Determinants of trust in a service provider: The moderating role of length of relationship. Journal of Services Marketing, 16(1), 35-50.

Colquitt, J. A., \& Rodell, J. B. (2011). Justice, trust, and trustworthiness: A longitudinal analysis integrating three theoretical perspectives. Academy of Management Journal, 54, 11831206.

Cook, J. D. \& Wall, T. D. (1980). New work attitude measures of trust, organizational commitment and personal need nonfulfillment. Journal of Occupational Psychology, 53, 39-52.

Deng, C., \& Ravichandran, T. (2017). How consumers perceive trustworthiness of providers in sharing economy: Effects of photos and commends on demand at Airbnb. Paper presented at the AMCIS 2017, Boston.

Dodds, P. S., Harris, K. D., Kloumann, I. M., Bliss, C. A., \& Danforth, C. M. (2011). Temporal patterns of happiness and information in a global social network: Hedonometrics and Twitter. PLoS ONE, 6(12), e26752. https://doi.org/10.1371/journal.pone.0026752

Doney, P. M., \& Cannon, J. P. (1997). An examination of the nature of trust in buyer-seller relationships. Journal of Marketing, 61(2), 35-51.

eMarketer (2017). Uber, Airbnb lead the way as sharing economy expands: 56.5 million people will use a sharing economy service this year. https://www.emarketer.com/Article/UberAirbnb-Lead-Way-Sharing-Economy-Expands/1016109 
Ellison, N. B., Hancock, J. T., \& Toma, C. L. (2011). Profile as promise: A framework for conceptualizing veracity in online dating self-presentations. New Media \& Society, 14(1), $1-18$.

Ellison, N., Heino, R., \& Gibbs, J. (2006). Managing impressions online: Self-presentation processes in the online dating environment. Journal of Computer-Mediated Communication, 11(2), 415-441.

Ert, E., Fleischer, A., \& Magen, N. (2016). Trust and reputation in the sharing economy: The role of personal photos in Airbnb. Tourism Management, 55, 62-73.

Ewert, A., \& Sibthorp, J. (2009). Creating outcomes through experiential education: The challenge of confounding variables. Journal of Experiential Education, 31(3), 376- 389.

Finch, H. (2005). Comparison of distance measures in cluster analysis with dichotomous data. Journal of Data Science, 3(1), 85-100.

Fleiss, J. L. (1971). Measuring nominal scale agreement among many raters. Psychological bulletin, 76(5), 378-382.

Fortune (2017). Airbnb's profits to top \$3 billion by 2020. http://fortune.com/2017/02/15/airbnbprofits/

Fruchterman, T. M. J., \& Reingold, E.M. (1991). Graph drawing by force-directed placement. Software - Practice and Experience, 21(11), 1129-1164.

Fryers, T. (2006). Work, identity, and health. Clinical Practice \& Epidemiology in Mental Health, 2, 12.

Gallup. (2014). In U.S., 55\% of workers get sense of identity from their job. Retrieved from http://www.gallup.com/poll/175400/workers-sense-identity-job.aspx 
Gefen, D. (2002). Customer loyalty in e-commerce. Journal of the Association for Information Systems, 3(1), 27-51.

Gibbs, J. L., Ellison, N. B., \& Heino, R. D. (2006). Self-presentation in online personals: The role of anticipated future interaction, self-disclosure, and perceived success in Internet dating. Communication Research, 33(2), 152-177.

Goffman, E. (1990). The Presentation of Self in Everyday Life. London: Penguin.

Guttentag, D. (2015). Airbnb: disruptive innovation and the rise of an informal tourism accommodation sector. Current Issues in Tourism, 18(12), 1192-1217

Haas, D. F., \& Deseran, F. A. (1981). Trust and symbolic exchange. Social Psychological Quarterly, 44, 3-13.

Hair, J. F., Ringle, C. M., \& Sarstedt, M. (2011). PLS-SEM: Indeed a silver bullet. Journal of Marketing theory and Practice, 19(2), 139-152.

Hawlitschek, F., Teubner, T., \& Weinhardt, C. (2016). Trust in the sharing economy. Die Unternehmung - Swiss Journal of Business Research and Practice, 70(1), 26-44.

Heo, C. Y. (2016). Sharing economy and prospects in tourism research. Annals of Tourism Research, 58, 166-170.

Higuchi, K. (2017a). A Two-Step Approach to Quantitative Content Analysis: KH Coder Tutorial using Anne of Green Gables (Part I). Ritsumeikan Social Sciences Review, http://www.ritsumei.ac.jp/file.jsp?id=325881

Higuchi, K. (2017b). A Two-Step Approach to Quantitative Content Analysis: KH Coder Tutorial using Anne of Green Gables (Part II). Ritsumeikan Social Sciences Review, http://www.ritsumei.ac.jp/file.jsp?id=346128 
Hoffman, D. L., Novak, T. P., \& Peralta, M. A. (1999). Building consumer trust in online environments: The case for information privacy. Communication of ACM, 42(4), 80-85.

Hong, I. B., \& Cho, H. (2011). The impact of consumer trust on attitudinal loyalty and purchase intentions in B2C e-marketplaces: Intermediary trust vs. seller trust. International Journal of Information Management, 31, 469-479.

InsideAirbnb.com (2015). Get the Data. Retrieved from http://insideairbnb.com/get-the-data.html

Johnson, D.S., \& Grayson, K. (2005). Cognitive and affective trust in service relationships. Journal of Business Research, 58(4), 500-507.

Karlsson, L., \& Dolnicar, S. (2016). Someone's been sleeping in my bed. Annals of Tourism Research, 58, 159-162.

Kim, J., \& Lee, J. R. (2011). The Facebook paths to happiness: Effects of the number of Facebook friends and self-presentation on subjective well-being. Cyberpsychology, Behavior and Social Networking, 14(6), 359-364.

Kim, J., \& Tussyadiah, I. P. (2013). Social networking and social support in tourism experience: The moderating role of online self-presentation strategies. Journal of Travel \& Tourism Marketing, 30(1), 78-92.

Labrecque, L. I., Markos, E. C., \& Milne, G. R. (2011). Online personal branding: processes, challenges, and implications. Journal of Interactive Marketing, 25(1), 37-50.

Landis, J. R., \& Koch, G. G. (1977). The measurement of observer agreement for categorical data. Biometrics, 33(1), 159-174.

Lauer, T.W., \& Deng, X. (2007). Building online trust through privacy practices. International Journal of Information Security, 6(5), 323-331. 
Lee, M., \& Turban, E. (2001). A trust model for consumer internet shopping. International Journal of Electronic Commerce, 6(1), 75-91.

Li, J., Moreno, A., \& Zhang, D. J. (2015). Agent behavior in the sharing economy: Evidence from Airbnb. SSRN Electronic Journal, January 2015. DOI: 10.2139/ssrn.2708279

Liu, J. N. K., \& Zhang, E. Y. (2014). An investigation of factors affecting customer selection of online hotel booking channels. International Journal of Hospitality Management, 39, 7183.

Luhmann, N. (1979). Trust and Power. Chichester: John Wiley.

Marshall, P. D. (2010). The promotion and presentation of the self: Celebrity as marker of presentational media. Celebrity Studies, 1(1), 35-48.

Marwick, A., \& Boyd, D. (2011). To see and be seen: Celebrity practice on Twitter. Convergence: The International Journal of Research into New Media Technologies, 17(2), 139-158.

Mayer, R. C., Davis, J. D., \& Schoorman, F. D. (1995). An integrative model of organisational trust. Academy of Management Review, 20(3), 709 - 734.

McAllister, D. J. (1995). Affect- and cognition-based trust as foundations for interpersonal cooperation in organizations. The Academy of Management Journal, 8(1), 24-59.

McKnight, D. H., Choudhury, V., \& Kacmar, C. (2002a). Developing and validating trust measures for ecommerce: an integrative typology. Information Systems Research, 13(3), $334-359$

McKnight, D. H., Choudhury, V., \& Kacmar, C. (2002b). The impact of initial consumer trust on intentions to transact with a web site: A trust building model. Strategic Information Systems, 11, 297-323. 
Orsatti, J., \& Riemer, K. (2012, January). Identity and self-presentation: from a representational to a performative lens in studying social media engagement in organisations. In ACIS 2012: Location, location, location: Proceedings of the 23rd Australasian Conference on Information Systems 2012 (pp. 1-12). ACIS.

Pavlou, P., \& Gefen, D. (2002). Building effective online marketplaces with institution-based trust. Information Systems Research, 15(1), 37-59.

Pons, P., \& Latapy, M. (2005). Computing communities in large networks using random walks. Journal of Graph Algorithms and Applications, 10(2), 191-218.

PWC (2016). The sharing economy grows up: How the UK has embraced the sharing economy. http://www.pwc.co.uk/issues/megatrends/collisions/sharingeconomy/outlook-for-thesharing-economy-in-the-uk-2016.html.

Raban, D. R. (2009). Self-presentation and the value of information in Q\&A websites. Journal of the Association for Information Science and Technology, 60(12), 2465-2473.

Ratnasingam, P., \& Pavlou, P. (2003). Technology trust in Internet-based interorganizational electronic commerce. Journal of Electronic Commerce in Organizations, 1(1), 17-41.

Reinecke, L., \& Trepte, S. (2014). Authenticity and well-being on social network sites: A twowave longitudinal study on the effects of online authenticity and the positivity bias in SNS communication. Computers in Human Behavior, 30, 95-102.

Rheingold, H. (1995). The Virtual Community: Finding Connection in a Computerized World. London: Secker \& Wargurg.

Richardson, L. (2015). Performing the sharing economy. Geoforum, 67, 121-129.

Ridings, C. M., Gefen, D., \& Arinze, B. (2002) Some antecedents and effects of trust in virtual communities. Journal of Strategic Information Systems, 11(3\&4), 271-295. 
Sönmez, S. F., \& Graefe, A. R. (1998). Determining future travel behavior from past travel experience and perceptions of risk and safety. Journal of Travel Research, 37(2), 171177.

Schwabel, D. (2009). Me 2.0: A Powerful Way to Achieve Brand Success. New York: Kaplan Publishers.

Shepherd, I. D. H. (2005). From Cattle and Coke to Charlie: Meeting the challenge of self marketing and personal branding. Journal of Marketing Management, 21, 589-606.

Sheppard, B. H., \& Sherman, D. M. (1998). The grammars of trust: A model and general implications. The Academy of Management Review, 23(3), 422-437.

Skift (2017). Airbnb is becoming an even bigger threat to hotels says a new report. Retrieved from https://skift.com/2017/01/04/airbnb-is-becoming-an-even-bigger-threat-to-hotelssays-a-new-report/

Sparks, B., \& Browning, V. (2011). The impact of online reviews on hotel booking intentions and perception of trust. Tourism Management, 32(6), 1310-1323.

Stanyer, J. (2008). Elected representatives, online self-presentation and the personal vote: Party, personality and webstyles in the United States and United Kingdom. Information, Communication \& Society, 11(3), 414-432.

Sztompka, P. (1999). Trust: A Sociological Theory. Cambridge: Cambridge University Press. Teubner, T., Saade, N., Hawlitschek, F., \& Weinhardt, C. (2016). It's only pixels, badges, and stars: On the economic value of reputation on Airbnb. Australasian Conference on Information Systems, Wollongong, Australia. 
Toma, C., Hancock, J., \& Ellison, N. (2008). Separating fact from fiction: An examination of deceptive self-presentation in online dating profiles. Personality and Social Psychology Bulletin, 34, 1023-1036.

Toutanova, K., Klein, D., Manning, C., \& Singer, Y. (2003). Feature-Rich Part-of-Speech Tagging with a Cyclic Dependency Network. In Proceedings of HLT-NAACL 2003, pp. 252-259.

Trepte, S., \& Reinecke, L. (2013). The reciprocal effects of social network site use and the disposition for self-disclosure: A longitudinal study. Computers in Human Behavior, 29, 1102-1112

Tussyadiah, I. P. (2016). Factors of satisfaction and intention to use peer-to-peer accommodation. International Journal of Hospitality Management, 55, 70-80.

Tussyadiah, I. P., \& Pesonen, J. (2016). Impacts of peer-to-peer accommodation use on travel pattern. Journal of Travel Research, 55(8), 1022-1040.

Tussyadiah, I. P., \& Zach, F. (2016). Identifying salient attributes of peer-to-peer accommodation experience. Journal of Travel \& Tourism Marketing, 34(5), 636-652.

Walsh, G., \& Beatty, S. (2007). Customer-based corporate reputation of a service firm: scale development and validation. Journal of the Academy of Marketing Science, 35(1), 127-143.

Walther, J. B. (1992). Interpersonal effects in computer-mediated interactions: A relational perspective. Communication Research, 19(1), 52-91.

Walther, J. B. (2007). Selective self-presentation in computer-mediated communication: Hyper personal dimensions of technology, language, and cognition. Computers in Human Behavior, 23, 2538-2557. 
Walther, J. B., \& Burgoon, J. K. (1992). Relational communication in computer-mediated interaction. Human Communication Research, 19(1), 50-88.

Wang, L., Law, R., Guillet, B. D., Hung, K., Fong, D. K. C. (2015). Impact of hotel website quality on online booking intentions: eTrust as a mediator. International Journal of Hospitality Management, 47, 108-115.

Yang, S.-B., Lee, K., Lee, H., Chung, N., Koo, C. (2016). Trust breakthrough in the sharing economy: An empirical study of Airbnb. PACIS 2016 Proceedings. 
Figure 1. Word co-occurrence networks: Austin, TX

Cluster 1: Travelers



Nodes $=34 ;$ Edges $=36 ;$ Density $=.057$

Cluster 2: Workers



Nodes $=35 ;$ Edges $=22 ;$ Density $=.037$ 

Figure 2. Word co-occurrence networks: Chicago, IL

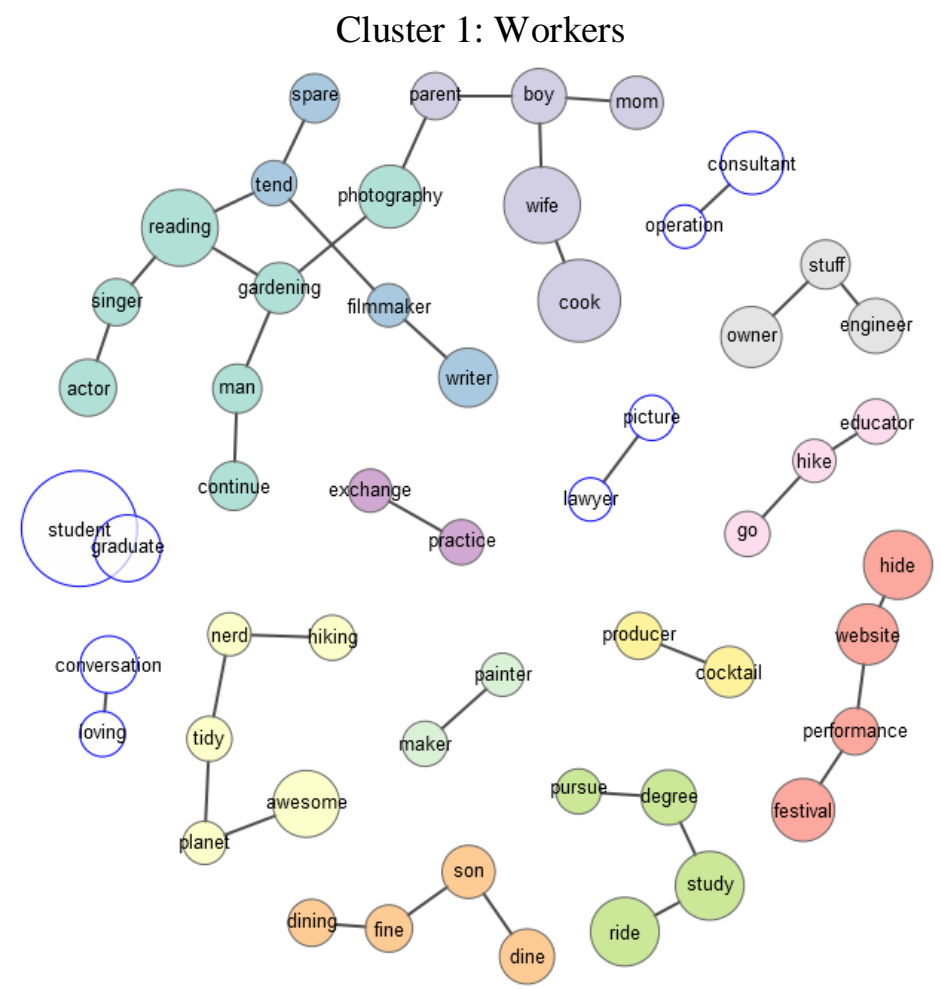

Nodes $=53 ;$ Edges $=39 ;$ Density $=.028$

\section{Cluster 2: Travelers}

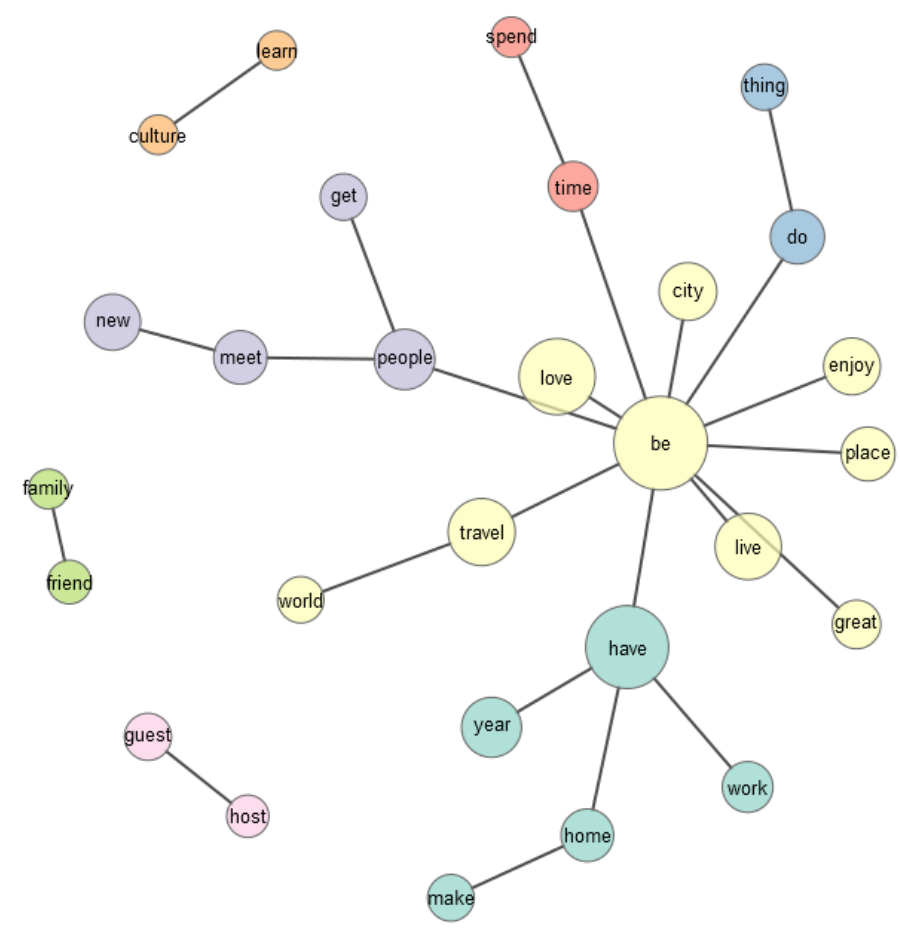

Nodes $=28 ;$ Edges $=24 ;$ Density $=.063$ 
Figure 3. Word co-occurrence network: New York, NY

Cluster 1: Travelers

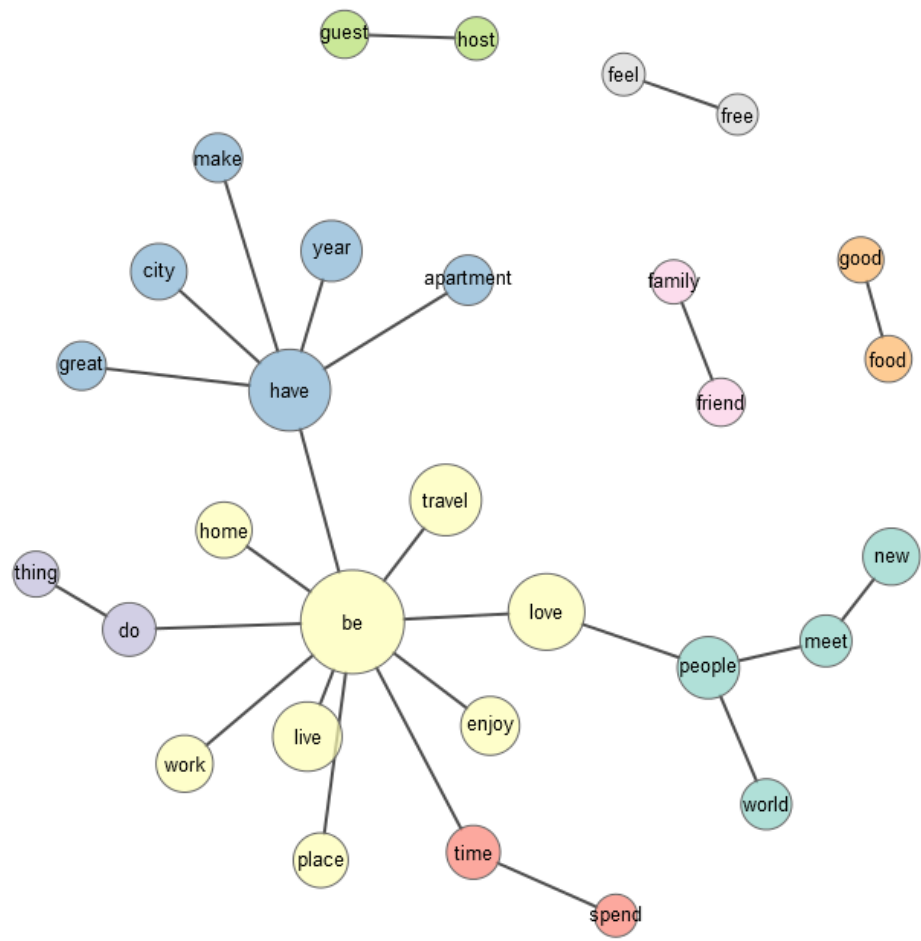

Nodes $=30 ;$ Edges $=25 ;$ Density $=.057$

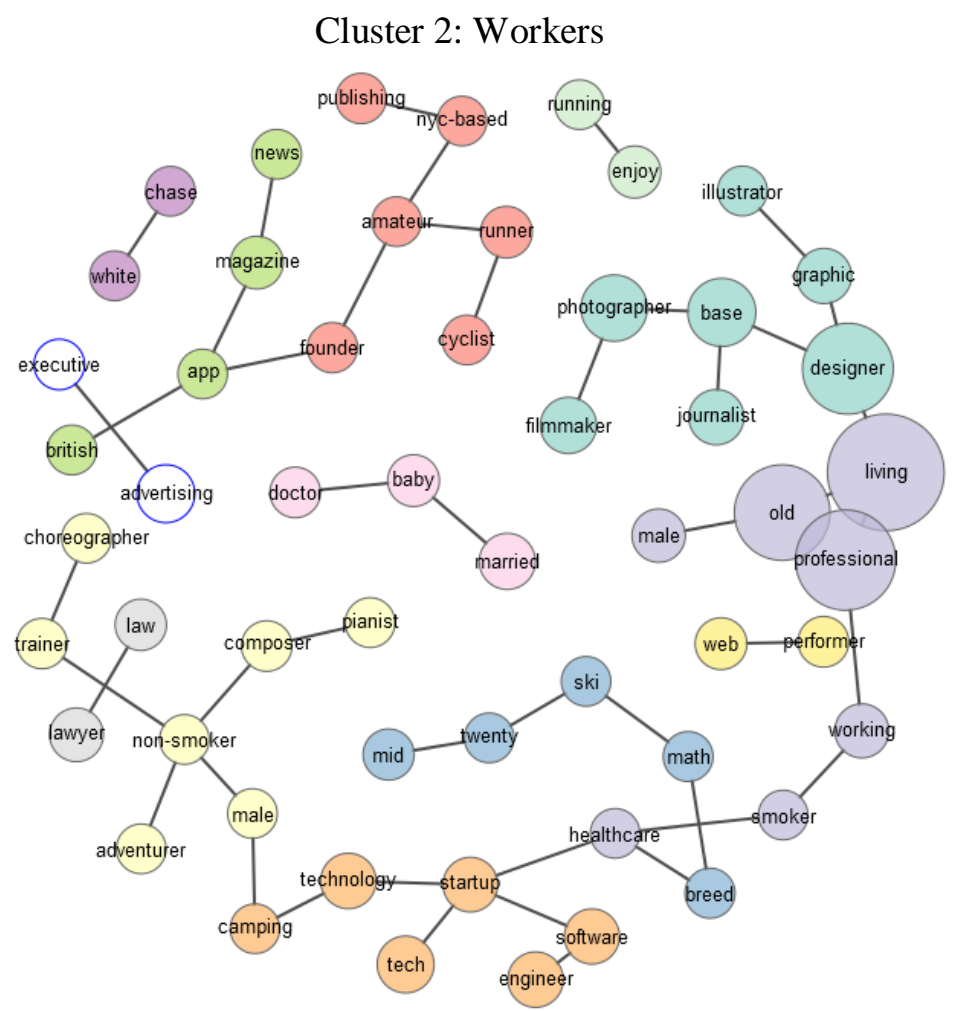

Nodes $=55 ;$ Edges $=49 ;$ Density $=.032$ 

Figure 4. Comparison of perceived trust and booking intention across Persona 1: "Travelers," Persona 2: "Workers," and Persona 3: "Hybrid."

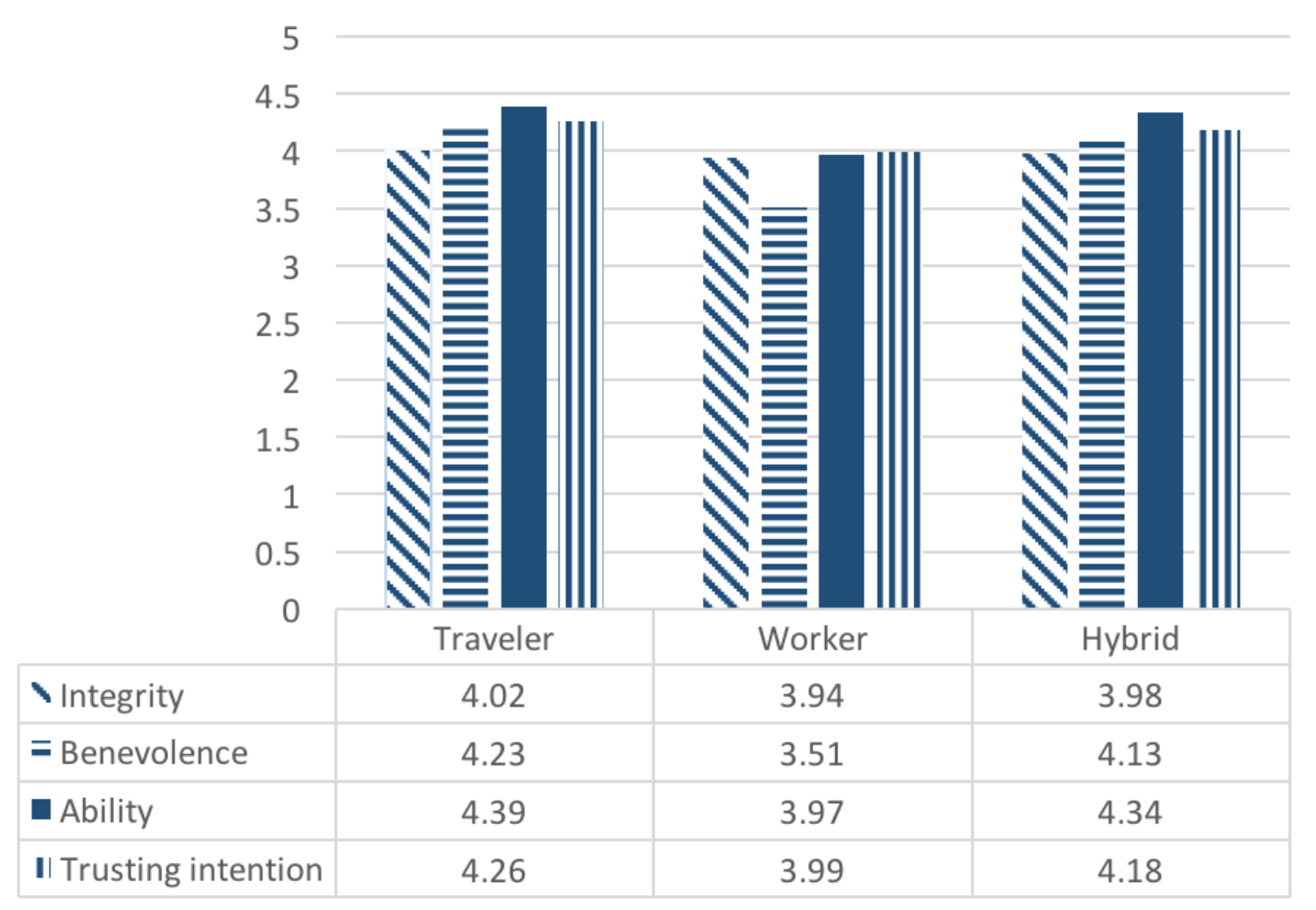


Table 1. Descriptive results of textual data

\begin{tabular}{lrrrrrrr}
\hline & Documents & Sentences & $\begin{array}{c}\text { Sentences/ } \\
\text { Document }\end{array}$ & Tokens & $\begin{array}{c}\text { Tokens/ } \\
\text { Document }\end{array}$ & $\begin{array}{c}\text { Tokens in } \\
\text { Analysis }\end{array}$ & $\begin{array}{c}\text { M } \\
\text { Fre }\end{array}$ \\
\hline Los Angeles, CA & 5,278 & 16,650 & 3.15 & 378,184 & 71.65 & 234,368 \\
Santa Cruz County, CA & 327 & 1,204 & 3.68 & 29,833 & 91.23 & 18,399 \\
San Francisco, CA & 2,581 & 7,893 & 3.06 & 185,251 & 71.77 & 113,859 \\
San Diego, CA & 951 & 3,273 & 3.44 & 78,773 & 82.83 & 48,895 \\
Oakland, CA & 506 & 1,586 & 3.13 & 39,738 & 78.53 & 24,297 \\
Washington, DC & 1,217 & 3,618 & 2.97 & 82,232 & 67.57 & 50,470 \\
Chicago, IL & 1,712 & 5,861 & 3.42 & 133,775 & 78.14 & 82,181 \\
New Orleans, LA & 794 & 2,578 & 3.25 & 62,918 & 79.24 & 38,743 \\
Boston, MA & 690 & 2,076 & 3.01 & 46,661 & 67.62 & 28,778 \\
New York, NY & 12,175 & 34,922 & 2.87 & 731,509 & 60.08 & 450,781 \\
Portland, OR & 1,201 & 4,526 & 3.77 & 117,334 & 97.70 & 72,041 \\
Nashville, TN & 686 & 2,586 & 3.77 & 60,838 & 88.69 & 37,518 \\
Austin, TX & 1,681 & 5,134 & 3.05 & 119,388 & 71.02 & 73,214 \\
Seattle, WA & 1,320 & 4,498 & 3.41 & 110,938 & 84.04 & 68,121 \\
\hline
\end{tabular}


Table 2. Cluster analyses: 2-cluster solution vs. 4-cluster solution




Table 3. Reliability of stimuli: Percent agreement and Fleiss' Kappa

\begin{tabular}{lccc}
\hline & $\begin{array}{c}\text { New York, NY } \\
(N=101)\end{array}$ & $\begin{array}{c}\text { Chicago, IL } \\
(N=100)\end{array}$ & $\begin{array}{c}\text { Austin, TX } \\
(N=100)\end{array}$ \\
\hline Persona 1: "Travelers" & $85 \%$ & $93 \%$ & $91 \%$ \\
Persona 2: "Workers" & $98 \%$ & $91 \%$ & $96 \%$ \\
\hline Fleiss' Kappa & $.69^{* * * *}$ & $.70^{* * *}$ & $.75^{* * * *}$ \\
\hline Note: $* * * p<.001$ & & &
\end{tabular}

Note: $* * * p<.001$ 
Table 4. Measurements of trust

\begin{tabular}{|c|c|c|}
\hline Construct and Definition & Scale & Literature \\
\hline $\begin{array}{l}\text { Trust in Platform: the } \\
\text { positive expectations that } \\
\text { the peer-to-peer } \\
\text { accommodation platform } \\
\text { can be trusted. }\end{array}$ & $\begin{array}{l}\text { TInP_1 - Peer-to-peer accommodation rental } \\
\text { services can generally be trusted. } \\
\text { TInP_2 - I trust peer-to-peer accommodation rental } \\
\text { services. } \\
\text { TInP_3 - I have great confidence in peer-to-peer } \\
\text { accommodation rental services. } \\
\text { TInP_4 - Peer-to-peer accommodation rental } \\
\text { services have high integrity. } \\
\text { TInP_5 - I can depend on peer-to-peer } \\
\text { accommodation rental services to do the right thing. } \\
\text { TInP_6 - Peer to-peer rental services can be relied } \\
\text { upon. }\end{array}$ & Walsh \& Beatty (2007) \\
\hline $\begin{array}{l}\text { Integrity: the expectation } \\
\text { that hosts adhere to a set of } \\
\text { principles that guests } \\
\text { consider to make the hosts } \\
\text { dependable and reliable. }\end{array}$ & $\begin{array}{l}\text { Integrity_1 - The host is honest with his/her guests. } \\
\text { Ntegrity_2 - The host acts sincerely in dealing with } \\
\text { his/her guests. } \\
\text { Integrity_3 - The host has sound principles. }\end{array}$ & $\begin{array}{l}\text { Colquitt \& Rodell } \\
\text { (2011) and Ridings et } \\
\text { al. (2002). }\end{array}$ \\
\hline $\begin{array}{l}\text { Benevolence: the } \\
\text { expectation that hosts feel } \\
\text { interpersonal care and } \\
\text { concern and are willing to } \\
\text { do good to guests beyond } \\
\text { egocentric profit motive. }\end{array}$ & $\begin{array}{l}\text { Bene_1 - The host is concerned about the welfare } \\
\text { of his/her guests. } \\
\text { Bene_2- The host genuinely cares about his/her } \\
\text { guests' needs. } \\
\text { Bene_3 - The host looks out for what is important } \\
\text { to his/her guests. } \\
\text { Bene_4 - The host goes out of his/her way to help } \\
\text { his/her guests. }\end{array}$ & $\begin{array}{l}\text { Colquitt \& Rodell } \\
\text { (2011) and Ridings et } \\
\text { al. (2002). }\end{array}$ \\
\hline $\begin{array}{l}\text { Ability: the expectation } \\
\text { that hosts have the required } \\
\text { skills and characteristics } \\
\text { that enable them to be } \\
\text { perceived as competent } \\
\text { within peer-to-peer } \\
\text { accommodation domain. }\end{array}$ & $\begin{array}{l}\text { Ability_1 - The host is qualified. } \\
\text { Ability_2 - The host is skilled. } \\
\text { Ability_3 - The host is experienced. } \\
\text { Ability_4 - The host is capable. }\end{array}$ & $\begin{array}{l}\text { Colquitt \& Rodell } \\
\text { (2011) and Ridings et } \\
\text { al. (2002). }\end{array}$ \\
\hline
\end{tabular}


Table 5. Results of confirmatory factor analysis

\begin{tabular}{lccccc}
\hline & $\begin{array}{c}\text { Trust in } \\
\text { Platform }\end{array}$ & Integrity & Benevolence & Ability & $\begin{array}{c}\text { Trusting } \\
\text { Intention }\end{array}$ \\
\hline TInP_1 & $\mathbf{0 . 8 5}$ & 0.37 & 0.33 & 0.33 & 0.34 \\
TInP_2 & $\mathbf{0 . 8 8}$ & 0.40 & 0.37 & 0.33 & 0.39 \\
TInP_3 & $\mathbf{0 . 8 9}$ & 0.39 & 0.36 & 0.34 & 0.38 \\
TInP_4 & $\mathbf{0 . 8 4}$ & 0.41 & 0.37 & 0.34 & 0.32 \\
TInP_5 & $\mathbf{0 . 8 5}$ & 0.44 & 0.37 & 0.35 & 0.34 \\
TInP_6 & $\mathbf{0 . 8 7}$ & 0.44 & 0.40 & 0.35 & 0.34 \\
Integrity_1 & 0.36 & $\mathbf{0 . 7 4}$ & 0.49 & 0.47 & 0.35 \\
Integrity_2 & 0.40 & $\mathbf{0 . 8 5}$ & 0.46 & 0.47 & 0.34 \\
Integrity_3 & 0.41 & $\mathbf{0 . 8 7}$ & 0.59 & 0.55 & 0.42 \\
Bene_1 & 0.40 & 0.55 & $\mathbf{0 . 8 7}$ & 0.53 & 0.37 \\
Bene_2 & 0.37 & 0.60 & $\mathbf{0 . 9 2}$ & 0.57 & 0.40 \\
Bene_3 & 0.38 & 0.59 & $\mathbf{0 . 9 1}$ & 0.58 & 0.43 \\
Bene_4 & 0.36 & 0.50 & $\mathbf{0 . 8 7}$ & 0.56 & 0.36 \\
Ability_1 & 0.36 & 0.49 & 0.57 & $\mathbf{0 . 8 7}$ & 0.45 \\
Ability_2 & 0.37 & 0.58 & 0.51 & $\mathbf{0 . 8 6}$ & 0.45 \\
Ability_3 & 0.29 & 0.51 & 0.57 & $\mathbf{0 . 8 6}$ & 0.47 \\
Intention & 0.41 & 0.45 & 0.44 & 0.53 & $\mathbf{1 . 0 0}$ \\
\hline
\end{tabular}


Table 6. Discriminant validity

\begin{tabular}{lccccccc}
\hline & $\begin{array}{c}\text { Cronbach's } \\
\text { Alpha }\end{array}$ & $\begin{array}{c}\text { Composite } \\
\text { reliability }\end{array}$ & $\mathbf{1}$ & $\mathbf{2}$ & $\mathbf{3}$ & $\mathbf{4}$ & $\mathbf{5}$ \\
\hline 1. Trust in Platform & 0.93 & 0.95 & $\mathbf{0 . 8 6}$ & & & & \\
2. Integrity & 0.75 & 0.86 & 0.48 & $\mathbf{0 . 8 2}$ & & & \\
3. Benevolence & 0.91 & 0.94 & 0.42 & 0.63 & $\mathbf{0 . 8 9}$ & & \\
4. Ability & 0.83 & 0.90 & 0.39 & 0.61 & 0.63 & $\mathbf{0 . 8 6}$ & \\
5. Trusting Intention & 1.00 & 1.00 & 0.41 & 0.45 & 0.44 & 0.53 & $\mathbf{1 . 0 0}$ \\
\hline
\end{tabular}

Note: Items on the diagonal (in bold) represent AVE scores 
Table 7. Comparison of consumer responses to host personae

\begin{tabular}{lccc}
\hline \multicolumn{1}{c}{ Variables } & $\begin{array}{c}\text { Persona 1: } \\
\text { "Travelers" }\end{array}$ & $\begin{array}{c}\text { Persona 2: } \\
\text { "Workers" }\end{array}$ & t-values \\
\hline Trust in platform & 3.90 & 3.79 & $2.02^{*}$ \\
Integrity & 4.02 & 3.94 & $1.96^{*}$ \\
Benevolence & 4.23 & 3.51 & $14.69 * * *$ \\
Ability & 4.39 & 3.97 & $9.07 * * *$ \\
Trusting intention & 4.26 & 3.99 & $4.52^{* * *}$ \\
\hline
\end{tabular}

Note: the responses have been obtained by a 5-point scale ranging from 1 (strongly disagree or extremely unlikely) to 5 (strongly agree or extremely likely); ${ }^{*} p<0.05, * * * p<0.001$ 
Table 8. Tests of confounding effects

\begin{tabular}{|c|c|c|c|}
\hline Variables & $\begin{array}{l}\text { Persona 1: } \\
\text { "Travelers" }\end{array}$ & $\begin{array}{l}\text { Persona 2: } \\
\text { "Workers" }\end{array}$ & Chi-square \\
\hline Accommodation experiences & & & \\
\hline $\begin{array}{l}\text { Previous experience staying in Airbnb or similar } \\
\text { before (Yes) }\end{array}$ & $48.8 \%$ & $51.2 \%$ & 1.10 \\
\hline Recent stay in a P2P accommodation & & & 3.67 \\
\hline Within the last six months & $51.3 \%$ & $48.7 \%$ & \\
\hline Within in a year & $48.4 \%$ & $51.6 \%$ & \\
\hline More than a year ago & $38.1 \%$ & $61.9 \%$ & \\
\hline \multicolumn{4}{|l|}{ Types of an accommodation stayed in } \\
\hline An entire house/apartment & $48.6 \%$ & $51.4 \%$ & 0.33 \\
\hline A private room & $52.8 \%$ & $47.2 \%$ & 2.52 \\
\hline A shared room & $46.2 \%$ & $53.8 \%$ & 0.01 \\
\hline \multicolumn{4}{|l|}{ Demographics } \\
\hline Gender (Female) & $52.1 \%$ & $47.9 \%$ & 3.80 \\
\hline Age $^{1}$ & - & - & 3.21 \\
\hline Highest level of education ${ }^{2}$ & - & - & 3.06 \\
\hline Annual household income ${ }^{3}$ & - & - & 15.41 \\
\hline \multicolumn{4}{|c|}{$\begin{array}{l}\text { Note: } 1 \text { includes six numbers of age subcategories: } 15 \text { to } 24 \text { years, } 25 \text { to } 34 \text { years, } 35 \text { to } 44 \text { years, } 45 \text { to } 54 \text { years, } 55 \\
\text { to } 64 \text { years, } 65 \text { years or above; } 2 \text { includes High School / GED, Some College, } 2 \text {-year College Degree, } 4 \text {-year Colle } \\
\text { Degree, Master's Degree, Doctoral Degree, and Professional Degree (Juris Doctor, Medical Doctor); } 3 \text { includes } \\
\text { under } \$ 20,000,20,000-29,999,30,000-39,999,40,000-49,999,50,000-59,999,60,000-69,999,70,000-79,999, \\
80,000-89,999,90,000-99,999,100,000-109,999,110,000-119,999,120,000-129,999,130,000-139,999,140,000- \\
149,999,150,000+.\end{array}$} \\
\hline
\end{tabular}




\section{Appendix A}

Table A1. Top 50 words in host description clusters: Austin, TX

\begin{tabular}{|c|c|c|c|c|c|c|c|c|}
\hline \multirow[b]{2}{*}{ No } & \multicolumn{4}{|c|}{ Cluster 1: Travelers } & \multicolumn{4}{|c|}{ Cluster 2: Workers } \\
\hline & Word & POS & $\begin{array}{l}\text { Conditional } \\
\text { Probability }\end{array}$ & $\begin{array}{c}\text { Jaccard } \\
\text { Index }\end{array}$ & Word & POS & $\begin{array}{l}\text { Conditional } \\
\text { Probability }\end{array}$ & $\begin{array}{c}\text { Jaccard } \\
\text { Index }\end{array}$ \\
\hline 1 & be & Verb & $1251(0.744)$ & 0.6924 & music & Noun & $353(0.210)$ & 0.1457 \\
\hline 2 & have & Verb & $811(0.482)$ & 0.6083 & live & Adj & $104(0.062)$ & 0.0601 \\
\hline 3 & love & Verb & $823(0.490)$ & 0.5198 & living & Noun & $84(0.050)$ & 0.0526 \\
\hline 4 & live & Verb & $630(0.375)$ & 0.3747 & wife & Noun & $63(0.037)$ & 0.0352 \\
\hline 5 & travel & Verb & $552(0.328)$ & 0.3393 & lay & Verb & $53(0.032)$ & 0.0339 \\
\hline 6 & home & Noun & $398(0.237)$ & 0.3333 & artist & Noun & $60(0.036)$ & 0.0335 \\
\hline 7 & enjoy & Verb & $437(0.260)$ & 0.3097 & writer & Noun & $43(0.026)$ & 0.0326 \\
\hline 8 & year & Noun & $428(0.255)$ & 0.2976 & lover & Noun & $48(0.029)$ & 0.0323 \\
\hline 9 & place & Noun & $318(0.189)$ & 0.2677 & hide & Verb & $30(0.018)$ & 0.0233 \\
\hline 10 & people & Noun & $327(0.195)$ & 0.2533 & reading & Noun & $38(0.023)$ & 0.023 \\
\hline 11 & new & Adj & $293(0.174)$ & 0.2509 & entrepreneur & Noun & $31(0.018)$ & 0.0213 \\
\hline 12 & do & Verb & $300(0.178)$ & 0.2438 & daughter & Noun & $33(0.020)$ & 0.0212 \\
\hline 13 & time & Noun & $288(0.171)$ & 0.2342 & resident & Noun & $23(0.014)$ & 0.0196 \\
\hline 14 & city & Noun & $312(0.186)$ & 0.2325 & outgoing & Adj & $27(0.016)$ & 0.0195 \\
\hline 15 & great & Adj & $256(0.152)$ & 0.21 & transplant & Noun & $28(0.017)$ & 0.0195 \\
\hline 16 & music & Noun & $353(0.210)$ & 0.2032 & gardening & Noun & $29(0.017)$ & 0.0194 \\
\hline 17 & make & Verb & $233(0.139)$ & 0.1937 & website & Adj & $23(0.014)$ & 0.0176 \\
\hline 18 & work & Verb & $269(0.160)$ & 0.1754 & passionate & Adj & $28(0.017)$ & 0.0175 \\
\hline 19 & food & Noun & $228(0.136)$ & 0.1591 & swim & Verb & $29(0.017)$ & 0.0174 \\
\hline 20 & go & Verb & $202(0.120)$ & 0.1586 & fashion & Noun & $10(0.006)$ & 0.0161 \\
\hline 21 & meet & Verb & $173(0.103)$ & 0.1513 & cycling & Noun & $21(0.012)$ & 0.0157 \\
\hline 22 & thing & Noun & $186(0.111)$ & 0.1444 & guy & Noun & $25(0.015)$ & 0.0156 \\
\hline 23 & stay & Verb & $174(0.104)$ & 0.1439 & married & Adj & $25(0.015)$ & 0.0156 \\
\hline 24 & get & Verb & $187(0.111)$ & 0.1432 & dancing & Noun & $26(0.015)$ & 0.0156 \\
\hline 25 & friend & Noun & $203(0.121)$ & 0.1382 & long-time & Adj & $11(0.007)$ & 0.014 \\
\hline 26 & guest & Noun & 169 (0.101) & 0.1373 & chef & Noun & $12(0.007)$ & 0.014 \\
\hline 27 & world & Noun & $171(0.102)$ & 0.133 & guitar & Noun & $14(0.008)$ & 0.0139 \\
\hline 28 & life & Noun & $182(0.108)$ & 0.1297 & mountain & Noun & $16(0.010)$ & 0.0139 \\
\hline 29 & good & Adj & 179 (0.106) & 0.1271 & interested & Adj & $17(0.010)$ & 0.0138 \\
\hline 30 & share & Verb & $157(0.093)$ & 0.1246 & rock & Noun & $19(0.011)$ & 0.0138 \\
\hline 31 & know & Verb & $149(0.089)$ & 0.1224 & breakfast & Noun & $21(0.012)$ & 0.0137 \\
\hline 32 & like & Verb & $155(0.092)$ & 0.1218 & super & Adj & $23(0.014)$ & 0.0137 \\
\hline 33 & see & Verb & $153(0.091)$ & 0.121 & taco & Noun & $23(0.014)$ & 0.0137 \\
\hline 34 & move & Verb & $163(0.097)$ & 0.1209 & drink & Noun & $23(0.014)$ & 0.0137 \\
\hline 35 & house & Noun & $146(0.087)$ & 0.1157 & web & Noun & $10(0.006)$ & 0.012 \\
\hline 36 & family & Noun & $162(0.096)$ & 0.115 & sale & Noun & $13(0.008)$ & 0.0119 \\
\hline 37 & find & Verb & 133 (0.079) & 0.114 & woman & Noun & $14(0.008)$ & 0.0119 \\
\hline 38 & local & Adj & $143(0.085)$ & 0.11 & base & Verb & $16(0.010)$ & 0.0119 \\
\hline 39 & favorite & Adj & $133(0.079)$ & 0.109 & education & Noun & $16(0.010)$ & 0.0119 \\
\hline 40 & want & Verb & $126(0.075)$ & 0.1067 & basketball & Noun & $18(0.011)$ & 0.0118 \\
\hline 41 & offer & Verb & 129 (0.077) & 0.1064 & camp & Verb & 19 (0.011) & 0.0118 \\
\hline 42 & best & Adj & $130(0.077)$ & 0.1053 & instructor & Noun & $9(0.005)$ & 0.01 \\
\hline 43 & happy & Adj & $136(0.081)$ & 0.1047 & soccer & Noun & $9(0.005)$ & 0.01 \\
\hline 44 & town & Noun & $136(0.081)$ & 0.1038 & worker & Noun & $9(0.005)$ & 0.01 \\
\hline 45 & explore & Verb & $136(0.081)$ & 0.1038 & email & Noun & $10(0.006)$ & 0.01 \\
\hline 46 & restaurant & Noun & $127(0.076)$ & 0.1036 & developer & Noun & $11(0.007)$ & 0.01 \\
\hline 47 & look & Verb & $132(0.079)$ & 0.1012 & laid-back & Adj & $11(0.007)$ & 0.01 \\
\hline 48 & host & Verb & $123(0.073)$ & 0.1 & camping & Noun & $11(0.007)$ & 0.01 \\
\hline
\end{tabular}




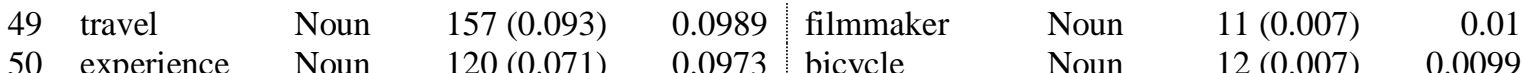

\begin{tabular}{llll|llll}
50 & experience Noun & $120(0.071)$ & 0.0973 & bicycle & Noun & $12(0.007)$ & 0.0099
\end{tabular}


Table A2 Top 50 words in host description clusters: Chicago, IL

\begin{tabular}{|c|c|c|c|c|c|c|c|c|}
\hline \multirow[b]{2}{*}{ No } & \multicolumn{4}{|c|}{ Cluster 1: Workers } & \multicolumn{4}{|c|}{ Cluster 2: Travelers } \\
\hline & Word & POS & $\begin{array}{l}\text { Conditional } \\
\text { Probability } \\
\end{array}$ & $\begin{array}{c}\text { Jaccard } \\
\text { Index }\end{array}$ & Word & POS & $\begin{array}{l}\text { Conditional } \\
\text { Probability }\end{array}$ & $\begin{array}{c}\text { Jaccard } \\
\text { Index }\end{array}$ \\
\hline 1 & student & Noun & $87(0.051)$ & 0.0572 & have & Verb & $861(0.503)$ & 0.6538 \\
\hline 2 & professional & Noun & $63(0.037)$ & 0.0372 & be & Verb & $1361(0.795)$ & 0.6067 \\
\hline 3 & cook & Verb & $59(0.034)$ & 0.0346 & love & Verb & $868(0.507)$ & 0.5139 \\
\hline 4 & sport & Noun & $56(0.033)$ & 0.0319 & live & Verb & $604(0.353)$ & 0.4383 \\
\hline 5 & reading & Noun & $46(0.027)$ & 0.0309 & travel & Verb & 717 (0.419) & 0.4096 \\
\hline 6 & wife & Noun & $50(0.029)$ & 0.0307 & people & Noun & $437(0.255)$ & 0.3887 \\
\hline 7 & outdoors & Noun & $47(0.027)$ & 0.0294 & year & Noun & $471(0.275)$ & 0.3637 \\
\hline 8 & native & Noun & $46(0.027)$ & 0.0265 & city & Noun & $474(0.277)$ & 0.3218 \\
\hline 9 & lover & Noun & $47(0.027)$ & 0.0265 & enjoy & Verb & $457(0.267)$ & 0.312 \\
\hline 10 & hide & Verb & $36(0.021)$ & 0.0255 & new & Adj & $418(0.244)$ & 0.3098 \\
\hline 11 & hang & Verb & $39(0.023)$ & 0.0254 & do & Verb & $336(0.196)$ & 0.2983 \\
\hline 12 & study & Verb & $41(0.024)$ & 0.0253 & meet & Verb & $298(0.174)$ & 0.2952 \\
\hline 13 & ride & Verb & $44(0.026)$ & 0.0252 & place & Noun & $354(0.207)$ & 0.2877 \\
\hline 14 & graduate & Noun & $35(0.020)$ & 0.024 & home & Noun & $343(0.200)$ & 0.2666 \\
\hline 15 & awesome & Adj & $37(0.022)$ & 0.024 & work & Verb & $372(0.217)$ & 0.2261 \\
\hline 16 & guy & Noun & $41(0.024)$ & 0.0238 & time & Noun & $327(0.191)$ & 0.2193 \\
\hline 17 & musician & Noun & $42(0.025)$ & 0.0238 & great & Adj & $254(0.148)$ & 0.2145 \\
\hline 18 & photography & Noun & $28(0.016)$ & 0.0214 & guest & Noun & $229(0.134)$ & 0.1926 \\
\hline 19 & festival & Noun & $33(0.019)$ & 0.0212 & go & Verb & $238(0.139)$ & 0.1872 \\
\hline 20 & consultant & Noun & $34(0.020)$ & 0.0212 & get & Verb & $232(0.136)$ & 0.1824 \\
\hline 21 & website & Adj & $26(0.015)$ & 0.02 & world & Noun & $231(0.135)$ & 0.1802 \\
\hline 22 & owner & Noun & $28(0.016)$ & 0.0199 & thing & Noun & $222(0.130)$ & 0.1794 \\
\hline 23 & writer & Noun & $29(0.017)$ & 0.0184 & make & Verb & $264(0.154)$ & 0.179 \\
\hline 24 & week & Noun & $24(0.014)$ & 0.0171 & host & Verb & $190(0.111)$ & 0.155 \\
\hline 25 & conversation & Noun & $26(0.015)$ & 0.0171 & share & Verb & $185(0.108)$ & 0.1535 \\
\hline 26 & actor & Noun & $26(0.015)$ & 0.0171 & neighb & Noun & $189(0.110)$ & 0.1493 \\
\hline 27 & engineer & Noun & $16(0.009)$ & 0.0159 & life & Noun & $190(0.111)$ & 0.1468 \\
\hline 28 & dine & Verb & $20(0.012)$ & 0.0158 & good & Adj & 200 (0.117) & 0.1465 \\
\hline 29 & boy & Noun & $20(0.012)$ & 0.0158 & favorite & Adj & $169(0.099)$ & 0.1464 \\
\hline 30 & native & Adj & $21(0.012)$ & 0.0157 & look & Verb & $191(0.112)$ & 0.1455 \\
\hline 31 & degree & Noun & .013) & 0.0157 & stay & Verb & $174(0.102)$ & 0.1445 \\
\hline 32 & property & Noun & $26(0.015)$ & 0.0156 & food & Noun & $207(0.121)$ & 0.1397 \\
\hline 33 & son & Noun & $21(0.012)$ & 0.0143 & friend & Noun & $217(0.127)$ & 0.1372 \\
\hline 34 & mom & Noun & $22(0.013)$ & 0.0143 & know & Verb & $168(0.098)$ & 0.1359 \\
\hline 35 & gardening & Noun & $16(0.009)$ & 0.0129 & music & Noun & $221(0.129)$ & 0.1344 \\
\hline 36 & roommate & Noun & $18(0.011)$ & 0.0129 & restaurant & Noun & $182(0.106)$ & 0.1329 \\
\hline 37 & chef & Noun & $19(0.011)$ & 0.0129 & like & Verb & $198(0.116)$ & 0.1307 \\
\hline 38 & cocktail & Noun & $22(0.013)$ & 0.0128 & explore & Verb & $200(0.117)$ & 0.1282 \\
\hline 39 & cycling & Noun & $11(0.006)$ & 0.0116 & experience & Noun & 139 (0.081) & 0.127 \\
\hline 40 & modern & Adj & $14(0.008)$ & 0.0115 & many & Adj & $147(0.086)$ & 0.1259 \\
\hline 41 & stuff & Noun & $15(0.009)$ & 0.0115 & host & Noun & $154(0.090)$ & 0.1238 \\
\hline 42 & continue & Verb & $16(0.009)$ & 0.0115 & other & Adj & $138(0.081)$ & 0.1177 \\
\hline 43 & earth & Noun & $17(0.010)$ & 0.0115 & travel & Noun & 195 (0.114) & 0.1177 \\
\hline 44 & spare & Adj & $18(0.011)$ & 0.0114 & happy & Adj & $126(0.074)$ & 0.1133 \\
\hline 45 & man & Noun & $18(0.011)$ & 0.0114 & try & Verb & $146(0.085)$ & 0.1087 \\
\hline 46 & enthusiast & Noun & $19(0.011)$ & 0.0114 & apartment & Noun & $140(0.082)$ & 0.1082 \\
\hline 47 & rest & Noun & $11(0.006)$ & 0.0101 & see & Verb & $142(0.083)$ & 0.108 \\
\hline 48 & producer & Noun & $11(0.006)$ & 0.0101 & visit & Verb & $133(0.078)$ & 0.1044 \\
\hline 49 & performance & Noun & $11(0.006)$ & 0.0101 & traveler & Noun & $146(0.085)$ & 0.1042 \\
\hline 50 & parent & Noun & $12(0.007)$ & 0.0101 & lot & Noun & $136(0.079)$ & 0.1041 \\
\hline
\end{tabular}


Table A3 Top 50 words in host description clusters: New York, NY

\begin{tabular}{|c|c|c|c|c|c|c|c|c|}
\hline \multirow[b]{2}{*}{ No } & \multicolumn{4}{|c|}{ Cluster 1: Travelers } & \multicolumn{4}{|c|}{ Cluster 2: Workers } \\
\hline & Word & POS & $\begin{array}{l}\text { Conditional } \\
\text { Probability }\end{array}$ & $\begin{array}{c}\text { Jaccard } \\
\text { Index }\end{array}$ & Word & POS & $\begin{array}{l}\text { Conditional } \\
\text { Probability }\end{array}$ & $\begin{array}{c}\text { Jaccard } \\
\text { Index }\end{array}$ \\
\hline 1 & be & Verb & $8729(0.717)$ & 0.6004 & living & Noun & $1001(0.082)$ & 0.0796 \\
\hline 2 & have & Verb & $4683(0.385)$ & 0.5279 & professional & Adj & $693(0.057)$ & 0.0628 \\
\hline 3 & love & Verb & $4710(0.387)$ & 0.4403 & old & Adj & $712(0.058)$ & 0.0568 \\
\hline 4 & travel & Verb & $4255(0.349)$ & 0.388 & designer & Noun & $572(0.047)$ & 0.0522 \\
\hline 5 & live & Verb & $4209(0.346)$ & 0.3584 & easy & Adj & $509(0.042)$ & 0.044 \\
\hline 6 & people & Noun & $2400(0.197)$ & 0.3323 & base & Verb & $266(0.022)$ & 0.0253 \\
\hline 7 & year & Noun & $3037(0.249)$ & 0.2868 & photographer & Noun & $258(0.021)$ & 0.0231 \\
\hline 8 & enjoy & Verb & $2208(0.181)$ & 0.2856 & lover & Noun & $277(0.023)$ & 0.0228 \\
\hline 9 & new & Adj & $2072(0.170)$ & 0.2645 & director & Noun & $126(0.010)$ & 0.0134 \\
\hline 10 & home & Noun & $1899(0.156)$ & 0.2545 & producer & Noun & $151(0.012)$ & 0.0129 \\
\hline 11 & city & Noun & $2138(0.176)$ & 0.2495 & advertising & Noun & 133 (0.011) & 0.0125 \\
\hline 12 & work & Verb & $2691(0.221)$ & 0.2416 & tech & Noun & $121(0.010)$ & 0.0113 \\
\hline 13 & place & Noun & $1821(0.150)$ & 0.2392 & graduate & Noun & $132(0.011)$ & 0.0111 \\
\hline 14 & time & Noun & $1691(0.139)$ & 0.2276 & filmmaker & Noun & $114(0.009)$ & 0.0105 \\
\hline 15 & do & Verb & $1722(0.141)$ & 0.2191 & architect & Noun & $116(0.010)$ & 0.0105 \\
\hline 16 & meet & Verb & $1415(0.116)$ & 0.2059 & married & Adj & $97(0.008)$ & 0.0104 \\
\hline 17 & world & Noun & $1527(0.125)$ & 0.1861 & engineer & Noun & $91(0.007)$ & 0.0096 \\
\hline 18 & apartment & Noun & $1497(0.123)$ & 0.1782 & technology & Noun & $117(0.010)$ & 0.0095 \\
\hline 19 & make & Verb & $1319(0.108)$ & 0.1672 & journalist & Noun & $101(0.008)$ & 0.0093 \\
\hline 20 & great & Adj & $1278(0.105)$ & 0.1663 & software & Noun & $94(0.008)$ & 0.0091 \\
\hline 21 & friend & Noun & $1190(0.098)$ & 0.1554 & graphic & Adj & 107 (0.009) & 0.0091 \\
\hline 22 & guest & Noun & $1130(0.093)$ & 0.1544 & startup & Noun & 104 (0.009) & 0.0085 \\
\hline 23 & go & Verb & $1475(0.121)$ & 0.1468 & finance & Noun & $93(0.008)$ & 0.0083 \\
\hline 24 & share & Verb & $1015(0.083)$ & 0.1357 & working & Noun & $86(0.007)$ & 0.0077 \\
\hline 25 & food & Noun & $1191(0.098)$ & 0.1355 & australian & Adj & $70(0.006)$ & 0.0073 \\
\hline 26 & like & Verb & $1194(0.098)$ & 0.1339 & lawyer & Noun & $72(0.006)$ & 0.0073 \\
\hline 27 & get & Verb & $1048(0.086)$ & 0.1338 & male & Noun & $79(0.006)$ & 0.0069 \\
\hline 28 & life & Noun & $1162(0.095)$ & 0.1327 & female & Noun & $61(0.005)$ & 0.0065 \\
\hline 29 & look & Verb & (0.089) & 0.1305 & non-profit & Adj & 77 & 0.0065 \\
\hline 30 & stay & Verb & $917(0.075)$ & 0.1268 & magazine & Noun & $65(0.005)$ & 0.0061 \\
\hline 31 & thing & Noun & $980(0.080)$ & 0.1266 & grad & Noun & $66(0.005)$ & 0.0055 \\
\hline 32 & good & Adj & $1080(0.089)$ & 0.1257 & enjoy & Adj & $56(0.005)$ & 0.0053 \\
\hline 33 & music & Noun & $1245(0.102)$ & 0.1215 & painter & Noun & $58(0.005)$ & 0.0051 \\
\hline 34 & neighborhood & Noun & $888(0.073)$ & 0.1167 & baby & Noun & $51(0.004)$ & 0.0049 \\
\hline 35 & know & Verb & $789(0.065)$ & 0.1123 & web & Noun & $53(0.004)$ & 0.0049 \\
\hline 36 & work & Noun & $1135(0.093)$ & 0.1108 & runner & Noun & $55(0.005)$ & 0.0047 \\
\hline 37 & host & Verb & $832(0.068)$ & 0.109 & nyc & Noun & $57(0.005)$ & 0.0047 \\
\hline 38 & happy & Adj & $826(0.068)$ & 0.1069 & law & Noun & $49(0.004)$ & 0.0043 \\
\hline 39 & travel & Noun & $999(0.082)$ & 0.1065 & $\operatorname{mid}$ & Adj & $39(0.003)$ & 0.0041 \\
\hline 40 & family & Noun & $771(0.063)$ & 0.1058 & surfing & Noun & $45(0.004)$ & 0.0041 \\
\hline 41 & lot & Noun & $841(0.069)$ & 0.1035 & educate & Verb & $44(0.004)$ & 0.0037 \\
\hline 42 & experience & Noun & $731(0.060)$ & 0.1024 & maker & Noun & $30(0.002)$ & 0.0035 \\
\hline 43 & explore & Verb & $890(0.073)$ & 0.1022 & canadian & Adj & $31(0.003)$ & 0.0035 \\
\hline 44 & art & Noun & $1038(0.085)$ & 0.1013 & performer & Noun & $40(0.003)$ & 0.0035 \\
\hline 45 & see & Verb & $751(0.062)$ & 0.1002 & doctor & Noun & $30(0.002)$ & 0.0033 \\
\hline 46 & love & Noun & $875(0.072)$ & 0.0988 & composer & Noun & $35(0.003)$ & 0.0033 \\
\hline 47 & host & Noun & $733(0.060)$ & 0.0966 & executive & Noun & $37(0.003)$ & 0.0033 \\
\hline 48 & many & Adj & $660(0.054)$ & 0.0925 & publishing & Noun & $34(0.003)$ & 0.0031 \\
\hline 49 & best & Adj & $671(0.055)$ & 0.0921 & trainer & Noun & $35(0.003)$ & 0.0031 \\
\hline 50 & restaurant & Noun & $650(0.053)$ & 0.0913 & founder & Noun & $34(0.003)$ & 0.0029 \\
\hline
\end{tabular}




\section{Appendix B}

\section{B1. Stimuli for Phase 1: Within-Subjects Design}

Questionnaire 1: New York, NY

Host Name: Neil

"I am a well-traveled art connoisseur who has lived in my neighborhood for 20+ years now. I would love to host you on your trip to the city as meeting people from around the world has brought much joy and satisfaction into my life. Welcome! My location is one of the most convenient in New York City, you can walk almost everywhere!" (Persona 1)

Host Name: Marjorie

"I work as an UX designer for one of the big banks in the Financial District. I design financial software for Technology Infrastructure department. I am studying towards a Masters' degree in Software Engineering through Harvard Extension - I was on campus in the spring semester, but I got a job in (NY), so I moved. I don't smoke and don't drink." (Persona 2)

Questionnaire 2: Chicago, IL

Host Name: Marjorie

"I love to go on global adventures and meet new people. My ferocious passion for learning is often fed by studying languages, cooking, watching interesting documentaries, etc. Because I am born and raised here, I can share all there is to know about the windy city. If you want restaurant recommendations, possible places to live permanently, shopping hot spots, or just cool tourist spots, I got you covered." (Persona 1)

\section{Host Name: Neil}

"Entrepreneur and enthusiast. Co-Founder of a tech company providing an online learning platform. Foodie, Snowboarder, Wanderlust, Wine Enthusiast, listening to Alternative Rock, and reading Economist. If you are not living on the edge, you are taking too much space." (Persona 2)

Questionnaire 3: Austin, TX

Host Name: Marjorie

"Hello! I am a world traveler and an organic gardener and a native Austinite. I love this city and all its parks, rivers, lakes and swimming spots, and bike paths. I have lived in Central and Downtown Austin for more than a decade and I like to share it with other travelers. I like to host not just for a little extra cash, but because I really like sharing this little corner of Austin with people visiting from all over. It is a great city and I am so happy to live here. I like for my guests 
to enjoy the place and to have a good time. If there is any question during your stay please feel free to ask." (Persona 1)

\section{Host Name: Neil}

"Senior Vice President of business development for a recording studio, Producer of HBO's Entourage's app, Co-creator of Platinum Life Street featuring Jamie Foxx \& Platinum Life Country presented by CMT! In addition to being a published author, he is co-founder and silent partner of a music software company. A 15-year record industry veteran, Neil has utilized his expertise in co-creation and editing of novels; budget construction; negotiating deals with authors; chief liaison; and executive in charge of $A \& R$ for an album. Neil's record industry experience includes: retail, marketing and promotion, and product management at indie labels." (Persona 2)

\section{B2. Stimuli for Phase 2: Between-Subjects Design}

\section{Host Name: Marjorie or Neil}

"I work as an UX designer for one of the big banks in the Financial District. I design financial software for Technology Infrastructure department. Because I am born and raised here, I can share all there is to know about the city. If you want restaurant recommendations, possible places to live permanently, shopping hot spots, or just cool tourist spots, I got you covered." (Persona 3: Hybrid) 


\section{Appendix C}

\section{Questionnaire}

Statement of consent:

"I give my voluntary consent to take part in this study."

Yes

No

Q1.1 How often do you travel, to domestic or international destinations, for leisure or business purposes?

About once every other year or less

About once a year

A few times a year

Monthly

Weekly

Q1.2 Have you stayed in Airbnb or other similar peer-to-peer accommodation rental services before?

Yes

No

(If "Yes" was selected)

Q1.3 When was your most recent stay in a peer-to-peer accommodation (such as Airbnb)?

Within the last six months

Within a year

More than a year ago

Q1.4 When staying at a peer-to-peer accommodation (such as Airbnb), which type of property have you used? Please select all that apply.

An entire home/apartment

A private room

A shared room

(If "No" was selected)

Q1.5 How familiar are you with Airbnb or other similar peer-to-peer accommodation rental services?

Not familiar at all

Slightly familiar

Moderately familiar

Very familiar

Extremely familiar

Q2.1 Please indicate the extent to which you agree with the following statements regarding peerto-peer accommodation rental services such as Airbnb.

Peer- to- peer accommodation

Strongly

disagree

Somewhat
disagree

rental services can generally

be trusted.

$\begin{array}{ccc}\begin{array}{c}\text { Neither } \\ \text { agree } \\ \text { nor disagree }\end{array} & \begin{array}{c}\text { Somewhat } \\ \text { agree }\end{array} & \begin{array}{c}\text { Strongly } \\ \text { agree }\end{array}\end{array}$


I trust peer-to-peer accommodation rental services.

I have great confidence in peer-to-peer accommodation rental services.

Peer-to-peer accommodation rental services has high

integrity.

I can depend on peer-to-peer accommodation rental services to do the right thing.

Peer-to-peer accommodation rental services can be relied upon.

$\begin{array}{lcccc}\text { Strongly } & \text { Somewhat } & \text { Neither } & \text { Somewhat } \\ \text { disagree } & \text { disagree } & \begin{array}{c}\text { agree } \\ \text { nor disagree }\end{array} & \begin{array}{c}\text { agree } \\ \text { agree }\end{array}\end{array}$

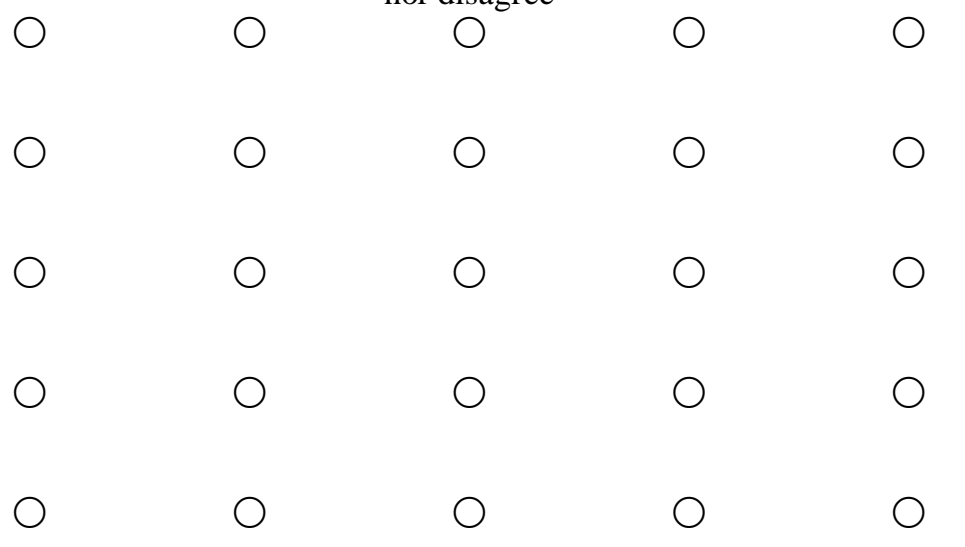

Q3.1 The following description is written by an individual who rents out his property on Airbnb. This description was posted under "About Host" section on Airbnb website. Please read carefully and answer the questions that follow.

(Respondents randomly assigned to one of four descriptions)

Host Name: Neil (Male)

Description:

"I love to go on global adventures and meet new people. My ferocious passion for learning is often fed by studying languages, cooking, watching interesting documentaries, etc. Because I am born and raised here, I can share all there is to know about the city. If you want restaurant recommendations, possible places to live permanently, shopping hot spots, or just cool tourist spots, I got you covered."

Q4.1 Based on the above description, please indicate to what extent you agree with the following statements regarding the host.

The host is honest with his/her guests.

The host acts sincerely in dealing with his/her guests. The host has sound principles. The host is concerned about the welfare of his/her guests. The host genuinely cares about his/her guests' needs. The host looks out for what is important to his/her guests. The host goes out of his/her way to help his/her guests

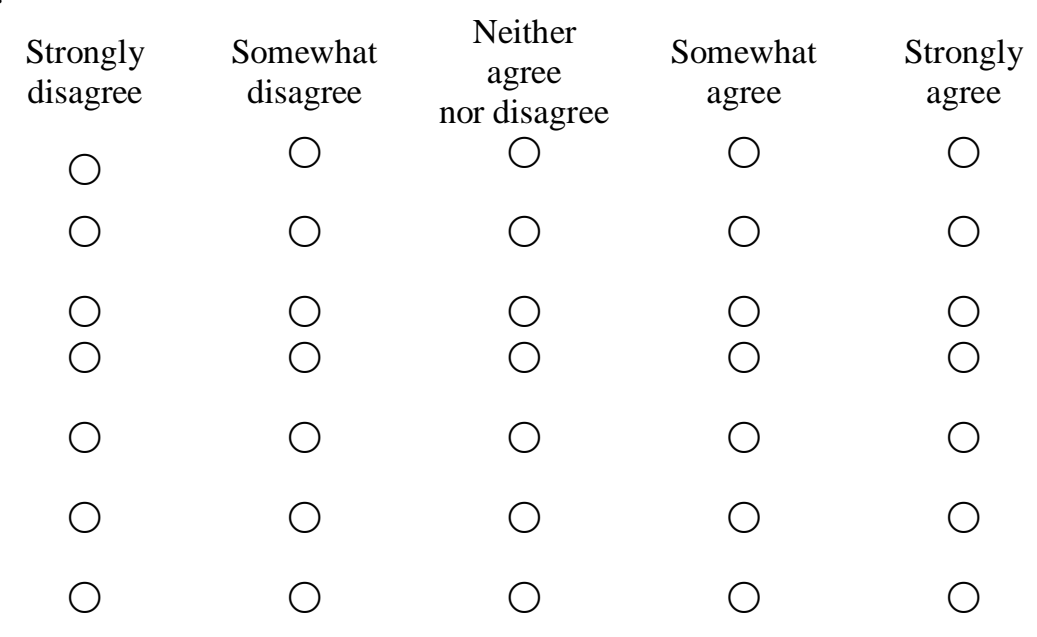




$\begin{array}{lccccc} & \begin{array}{c}\text { Strongly } \\ \text { disagree }\end{array} & \begin{array}{c}\text { Somewhat } \\ \text { disagree }\end{array} & \begin{array}{c}\text { Neither } \\ \text { agree } \\ \text { nor disagree }\end{array} & \begin{array}{c}\text { Somewhat } \\ \text { agree }\end{array} & \begin{array}{c}\text { Strongly } \\ \text { agree }\end{array} \\ \text { The host is qualified. } & \bigcirc & \bigcirc & \bigcirc & \bigcirc & \bigcirc \\ \text { The host is skilled. } & \bigcirc & \bigcirc & \bigcirc & \bigcirc & \bigcirc \\ \text { The host is experienced. } & \bigcirc & \bigcirc & \bigcirc & \bigcirc & \bigcirc \\ \text { The host is capable. } & \bigcirc & \bigcirc & \bigcirc & \bigcirc & \bigcirc\end{array}$

Q4.2 If the price, location, and amenities of this accommodation suit your need and preference, how likely are you to rent from this host?

Extremely unlikely

Somewhat unlikely

Neither likely nor unlikely

Somewhat likely

Extremely likely

Q5.1 What is your gender?

Male

Female

Q5.2 What is your age?

(Dropdown Menu)

Q5.3 What is the highest level of education you have completed?

$\begin{array}{ll}\text { Less than High School } & \text { 4-year College Degree } \\ \text { High School / GED } & \text { Masters Degree } \\ \text { Some College } & \text { Doctoral Degree } \\ \text { 2-year College Degree } & \text { Professional Degree (JD, MD) }\end{array}$

Q5.4 What is your combined annual household income before taxes?

(Dropdown Menu)

Q5.6 In which state do you currently reside?

(Dropdown Menu) 